\title{
Review Paper \\ Recombinant Lactococcus, a New Approach to Oral Vaccines
}

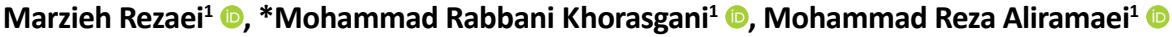

1. Department of Cell \& Molecular Biology and Microbiology, Faculty of Science and Biotechnology, University of Isfahan, Isfahan, Iran.

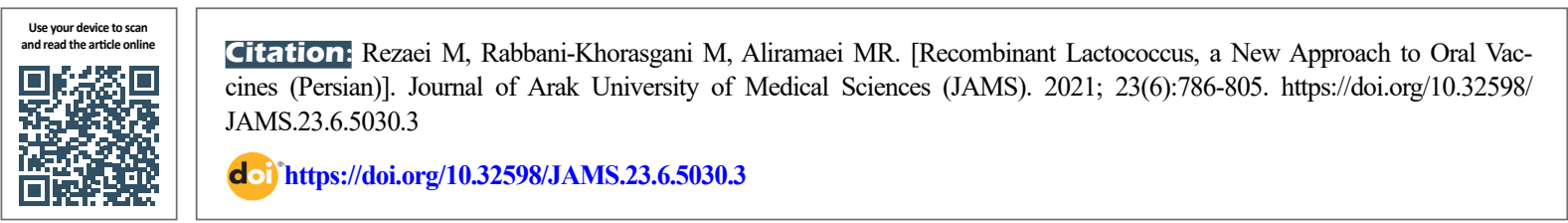

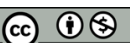

Article Info:

Received: 26 Feb 2020

Accepted: 12 Aug 2020

Available Online: 01 Feb 2021

Keywords:

Immunity, Lactococ-

cus lactis, Mucosal,

Vaccine

\section{A B STRACT}

Background and Aim The genus of Lactococcus lactis belonging to the Lactic Acid Bacteria (LAB) group, is a gram-positive, faculative anaerobic, non-spore-forming, and non-motile bacterium. The present study aimed to introduce $L A B$, especially non-pathogenic, non-invasive, and safe Lactococcus lactis. Accordingly, we examined the previous studies concerning the advantages, limitations, promotion methods, and future prospects of oral vaccines based on this bacterium. This is because it is a potentially promising strategy for the vaccine production and prevention of some infectious diseases.

Methods \& Materials In this review article, 62 studies related to Lactococcus lactis and its application in producing oral vaccines were collected through searching databases, such as PubMed, Google Scholar, Scopus published from 1981 to 2020.

Ethical Considerations This article was approved by the Ethical Research Committee of Arak University of Medical Sciences with the number 1396/99.

Results Lactococcus lactis, as a safe microorganism, is widely used in the food industry. Live recombinant Lactococcus lactis as a "biologic drug" is orally administered as one of the live vaccines expressing viral and bacterial antigens.

Conclusion Recombinant Lactococcus-based vector can be suitable substitutes for live attenuated vaccines. Moreover, it can be a safe and food-grade host for manufacturing the desired products of human consumption over other systems. It also presents a high potential for vaccine delivery, especially through mucosal methods to prevent or treat certain diseases.

\section{Extended Abstract}

\section{Introduction}

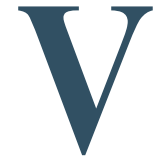

accines used to prevent and control pathogens include DNA vaccines, subunit vaccines, attenuated live vaccines, as well as vector (carrier) vaccines. Current strategies have focused on developing novel vaccines against infectious diseases; they are based on iden- tifying the immunogenic antigens capable of eliciting the necessary immune response to fight pathogens and their delivery system [7]. The present review study aimed to introduce non-pathogenic, non-invasive, and safe Lactococcus lactis bacteria. Furthermore, we evaluated the advantages and limitations of using recombinant Lactococcus lactisbased vaccines; review studies on oral vaccines based on them; vaccine promotion methods and future prospects, as a promising strategy for vaccine production, and preventing some infectious diseases.

\section{* Corresponding Author:}

Mohammad Rabbani Khorasgani, PhD.

Address: Department of Cell \& Molecular Biology and Microbiology, Faculty of Science and Biotechnology, University of Isfahan, Isfahan, Iran

Tel: +98 (313) 7932469

E-mail: m.rabbani@biol.ui.ac.ir 


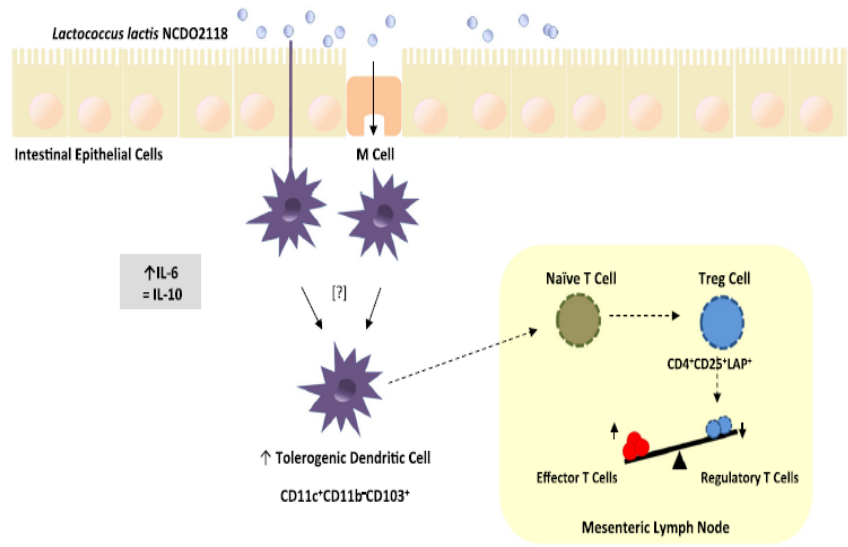

Figure 1. The mechanism of the anti-inflammatory effect of the oral administration of Lactococcus lactis strain NCDO2118 [31]

\section{Materials and Methods}

In this review article, 62 articles related to Lactococcus and its wide applications concerning oral vaccine production were collected from 1998 to 2020. Accordingly, we searched the following databases: Scopus, PubMed, and Google Scholar databases. The keywords used in this study included "Immunity, Lactococcus lactis, and Mucosal, Vaccine" (Figures 1, 2, 3, 4 \& Table 1).

\section{Results}

Lactococcus lactis is Generally Recognized As Safe (GRAS) and can be widely used in the food industry. Live recombinant Lactococcus lactis, as a biopharmaceutical, is administered orally as a live vaccine expressing viral and bacterial antigens.

\section{Discussion and Conclusion}

Vectors based on recombinant lactococci can be desirable alternatives to attenuated strain vaccines. Furthermore, they can be considered as a food-grade and safe host for producing human products, compared to other manufacturing systems. It also has a high potential for vaccine delivery, especially through mucosal methods for the prevention or treatment of some diseases. Additionally, Lactococcus lactis is among the most suitable cellular plants for the expression and secretion of heterologous proteins. A reason for the widespread use of this bacterium is the rapid secretion of protein in this bacterium and the feasible purification of the protein. Moreover, Lactococcus lactis is an efficient host for producing recombinant proteins for therapeutic purposes [34]. Lactococci, for several main reasons, can induce mucosal immunity (secretory IgA secretion) and systemic immunity, resist acidic gastric conditions, bind to the intestinal

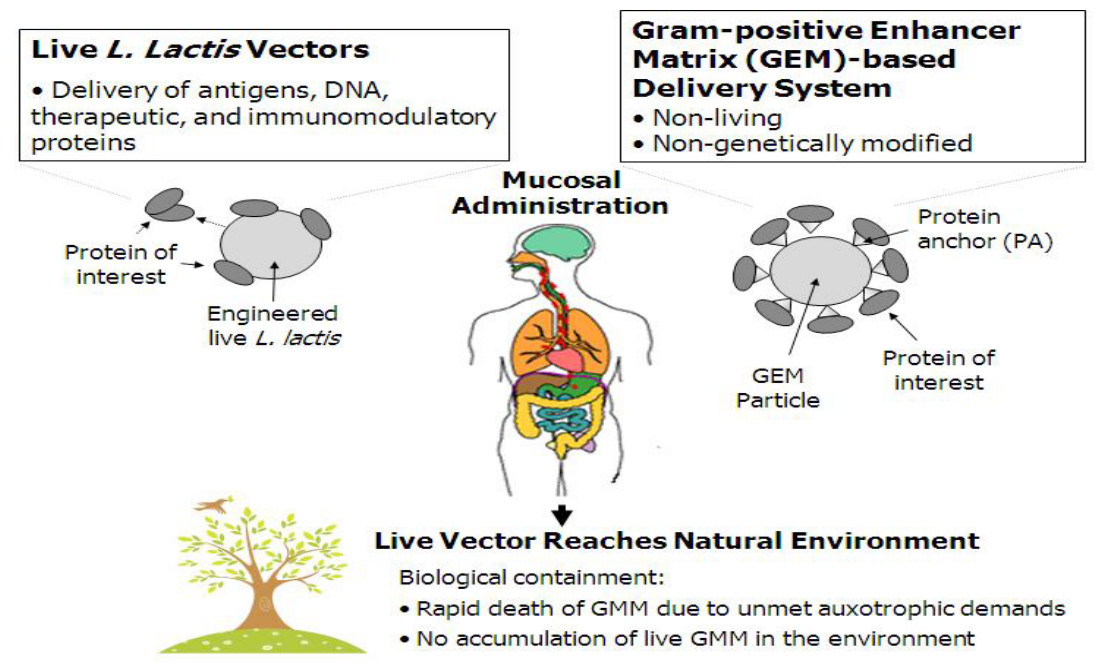

Figure 2. Anchor protein antigens delivery system purified with GEM particles [33] 


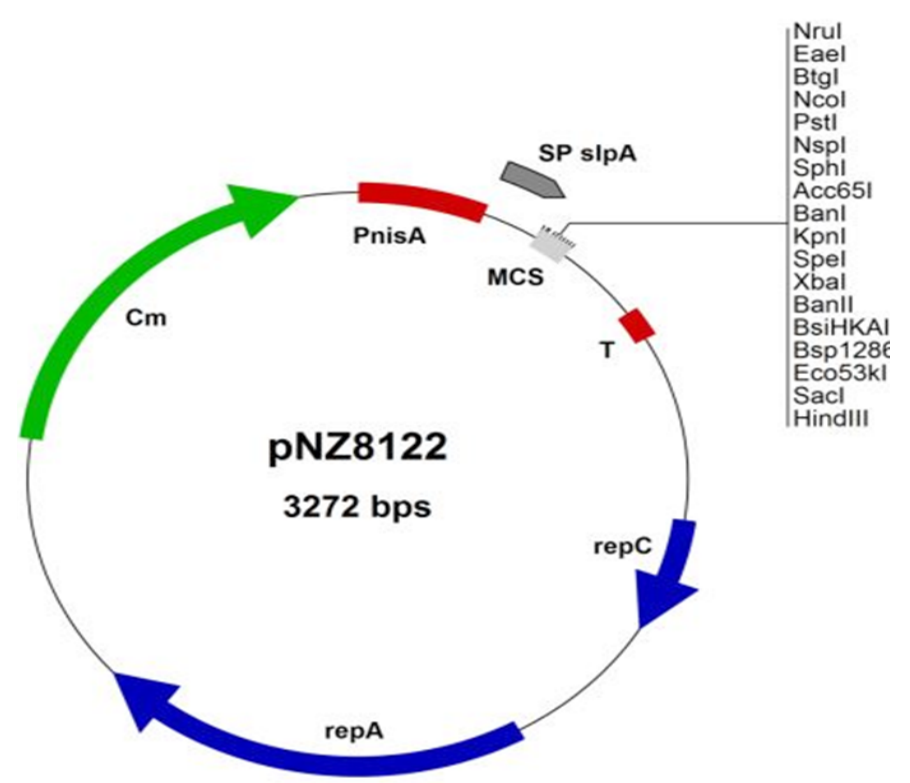

\begin{tabular}{|l|l|l|l|l|l|}
\hline & Type & Start & End & Name & Description \\
\hline & Promoter & 3 & 203 & PnisA & nisin $A$ promoter region \\
\hline & Region & 204 & 296 & SP slpA & Signal sequence of s/pA gene \\
\hline & Region & 297 & 352 & MCS & Multiple Cloning Site \\
\hline Terminator & 498 & 550 & T & Termination sequence of pepN gene \\
\hline & Gene & 893 & 1102 & repC & Replication gene $C$ \\
\hline & Gene & 1371 & 2069 & repA & Replication gene $A$ \\
\hline $\begin{array}{l}\text { Selectable } \\
\text { Marker }\end{array}$ & 2529 & 3179 & Cm (cat) & Chloramphenicol resistance \\
\hline
\end{tabular}

Figure 3. The gene map of pNZ8122 expression vector in Lactococcus lactis host [36, 49]

epithelium, and enhance the immune response as an adjuvant. Besides, the poor immune response against them, less immunity tolerance to them, also less adverse effects make it an appropriate option of live vectors in immunotherapy and immunoprophylaxis. With these characteristics, LABbased vectors are a suitable alternative to vaccines for the attenuated strains of pathogenic microorganisms, liposomes, and microparticles [1]. Recombinant lactococcus, as a food-grade safe host for producing the desired product, food, or other human consumption is safer than other production systems. However, using such genetically modified microorganisms requires extensive clinical and controlled

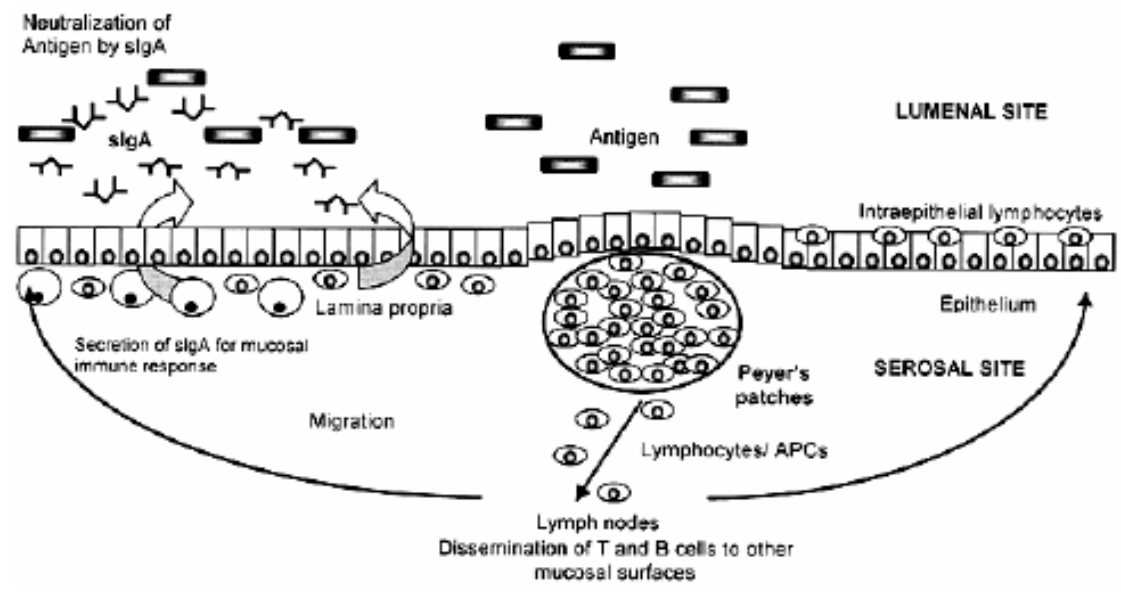

Figure 4. The induction of mucosal immune response during oral vaccine use 
Table 1. Experiences with using recombinant Lactococcus lactis as an oral vaccine

\begin{tabular}{|c|c|c|c|c|c|}
\hline & Target Microorganisms & Antigen & Findings & Study Methods & Reference \\
\hline \multirow{8}{*}{ 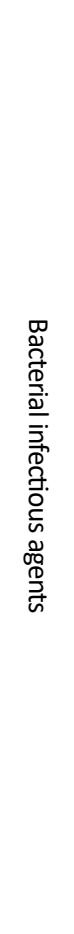 } & Brucela Milli Tennessee & Omp16-IL2 & $\begin{array}{l}\text { Producing recombinant Omp16 fusion protein (interleukin-2 } \\
\text { incorporated) \& producing recombinant Lactococcus lactis } \\
\text { MG1363 strain carrying this immunogenic antigen as an oral } \\
\text { vaccine against brucellosis. }\end{array}$ & $\begin{array}{l}\text { In vivo on } \\
\text { animals }\end{array}$ & {$[38,50]$} \\
\hline & Helicobacter pylori & CagL & $\begin{array}{l}\text { Expressing CagL and developing a recombinant strain of Lac- } \\
\text { tococcus lactis MG1363 expressing CagL protein as an oral } \\
\text { vaccine against Helicobacter pylori. }\end{array}$ & $\begin{array}{l}\text { In vivo on } \\
\text { animals }\end{array}$ & {$[51]$} \\
\hline & Clostridium difficile & Toxin B & $\begin{array}{l}\text { Toxin B cloning and expression in Lactococcus lactis with the } \\
\text { aim of future oral vaccine use. }\end{array}$ & In vitro & {$[52]$} \\
\hline & Helicobacter pylori & UreB & $\begin{array}{l}\text { Developing the recombinant strain of Lactococcus lactis ex- } \\
\text { pressing UreB, increase in serum IgG and fecal IgA levels after } \\
\text { the oral administration of the recombinant strain and protec- } \\
\text { tive effect after challenge with Helicobacter pylori. }\end{array}$ & $\begin{array}{l}\text { In vivo on } \\
\text { animals }\end{array}$ & [53] \\
\hline & $\begin{array}{l}\text { Enterotoxic Escherichia } \\
\text { coli ETEC K88 }\end{array}$ & $\mathrm{F} 4$ & $\begin{array}{l}\text { Increase in serum IgG and fecal IgA levels after the oral ad- } \\
\text { ministration of recombinant Lactococcus lactis and protective } \\
\text { effect during challenge with ETEC. }\end{array}$ & $\begin{array}{l}\text { In vivo on } \\
\text { animls }\end{array}$ & [17] \\
\hline & Listeria monocytogenes & LLO & $\begin{array}{l}\text { Increase in IgG and lethal T lymphocyte levels after the oral } \\
\text { administration of recombinant Lactococcus lactis and protec- } \\
\text { tive effect during challenge with Listeria monocytogenes. }\end{array}$ & $\begin{array}{l}\text { In vivo on } \\
\text { animals }\end{array}$ & [54] \\
\hline & Yersiniasodotuberculosis & LcrV & $\begin{array}{l}\text { Increased serum IgG and IgA levels and increased cellular im- } \\
\text { mune response after the oral administration of recombinant } \\
\text { Lactococcus strain and protective effect during challenge with } \\
\text { Yersiniasodotuberculosis. }\end{array}$ & $\begin{array}{l}\text { In vivo on } \\
\text { animals }\end{array}$ & [55] \\
\hline & Ariziplottrix rosiopathy & SpaA & $\begin{array}{l}\text { Increase in serum IgG and fecal IgA levels after the oral admin- } \\
\text { istration of recombinant strain of Lactococcus lactis and pro- } \\
\text { tective effect against inoculation with Ariziplotrix rosiopathy. }\end{array}$ & $\begin{array}{l}\text { In vivo on } \\
\text { animals }\end{array}$ & {$[56]$} \\
\hline \multirow{5}{*}{ 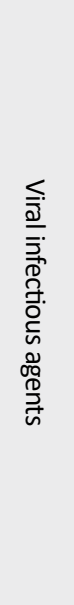 } & HIV & $\begin{array}{l}\text { V2-V4 Loop } \\
\text { Coating } \\
\text { Protein }\end{array}$ & $\begin{array}{l}\text { Increase in serum IgG and fecal lgA levels and increase cellular } \\
\text { immune response after the oral administration of recombi- } \\
\text { nant Lactococcus lactis strain and decrease in viral load after } \\
\text { challenge with HIV vaccine expressing HIV coat protein. }\end{array}$ & $\begin{array}{l}\text { In vivo on } \\
\text { animals }\end{array}$ & [45] \\
\hline & Dengue virus & EDIII & $\begin{array}{l}\text { The elevation of IgG and virus-neutralizing antibodies after } \\
\text { the oral administration of recombinant Lactococcus strain } \\
\text { expressing a viral antigen. }\end{array}$ & $\begin{array}{l}\text { In vivo on } \\
\text { animals }\end{array}$ & [57] \\
\hline & Rotavirus & VP7 & $\begin{array}{l}\text { The elevation of IgG and virus-neutralizing antibodies after } \\
\text { the oral administration of recombinant Lactococcus strain } \\
\text { expressing a viral antigen. }\end{array}$ & $\begin{array}{l}\text { In vivo on } \\
\text { animals }\end{array}$ & [58] \\
\hline & Rotavirus & VP4 & $\begin{array}{l}\text { Increase in serum IgG level, IgA level in feces and secretions, } \\
\text { cellular immune response, and virus-neutralizing antibodies } \\
\text { after the oral administration of recombinant Lactococcus } \\
\text { strain expressing the viral antigen. }\end{array}$ & $\begin{array}{l}\text { In vivo on } \\
\text { animals }\end{array}$ & [59] \\
\hline & TGEV & S protein & $\begin{array}{l}\text { Increase in serum IgG level, IgA level in feces, and virus-neu- } \\
\text { tralizing antibodies after the oral administration of recombi- } \\
\text { nant Lactococcus strain expressing the viral antigen. }\end{array}$ & $\begin{array}{l}\text { In vivo on } \\
\text { animals }\end{array}$ & {$[60]$} \\
\hline \multirow{2}{*}{ 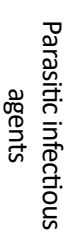 } & Rodent malaria & Msp1 & $\begin{array}{l}\text { Increase in serum IgG and decrease in parasitism after the } \\
\text { oral administration of recombinant Lactococcus strain ex- } \\
\text { pressing the antigen and during challenge with Plasmodium } \\
\text { parasites. }\end{array}$ & $\begin{array}{l}\text { In vivo on } \\
\text { animals }\end{array}$ & [61] \\
\hline & Giardia Lamblia & CWP2 & $\begin{array}{l}\text { Increase in fecal IgA and decrease in the number of excretory } \\
\text { cysts after the oral administration of recombinant antigen- } \\
\text { expressing Lactococcus strain during challenge with Giardia. }\end{array}$ & $\begin{array}{l}\text { In vivo on } \\
\text { animals }\end{array}$ & {$[62]$} \\
\hline \multirow{3}{*}{ 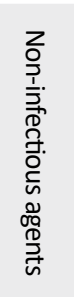 } & $\begin{array}{l}\text { Inflammatory bowel } \\
\text { disease (crown shape) }\end{array}$ & $\begin{array}{l}\text { Interleukin } \\
\quad 10\end{array}$ & $\begin{array}{l}\text { The expression of interleukin } 10 \text { in recombinant Lactococcus } \\
\text { lactis by replacement with thymidylate synthase gene. }\end{array}$ & $\begin{array}{l}\text { In vivo on } \\
\text { humans; phase } \\
\text { one: clinical }\end{array}$ & {$[30,43]$} \\
\hline & $\begin{array}{l}\text { Inflamed intestine (coli- } \\
\text { tis with the ulcer) }\end{array}$ & $\begin{array}{l}\text { Interleukin } \\
\quad 10\end{array}$ & $\begin{array}{l}\text { The expression of interleukin } 10 \text { in recombinant Lactococcus } \\
\text { lactis by replacement with thymidylate synthase gene. }\end{array}$ & $\begin{array}{l}\text { In vivo on } \\
\text { humans }\end{array}$ & [30] \\
\hline & $\begin{array}{l}\text { Oral mucositis (inflam- } \\
\text { mation of the oral } \\
\text { mucosa) }\end{array}$ & TFF1 factor & $\begin{array}{l}\text { The expression of trophovirus factor in recombinant Lacto- } \\
\text { coccus lactis by replacement with thymidylate synthase gene. }\end{array}$ & $\begin{array}{l}\text { In vivo on } \\
\text { humans; phase } \\
\text { one: clinical }\end{array}$ & [44] \\
\hline
\end{tabular}


studies and the proper evaluation of the performance and safety of such drugs, especially for humans.

\section{Ethical Considerations}

Compliance with ethical guidelines

This article was approved by the Ethical Research Committee of Arak University of Medical Sciences with the number 1396/99.

Funding

This research did not receive any grant from funding agencies in the public, commercial, or non-profit sectors.

\section{Authors' contributions}

All authors met the standard criteria for writing based on the recommendations of the International Committee of Publishers of Medical Journals (ICMJE).

\section{Conflicts of interest}

The authors stated no conflicts of interest. 
$5,9,0$ ditio

\title{
لاكتوكوكوس نوتركيب: رهيافتى نوين براى دستيابى به واكسنهاى دهانى
}

\author{
مرضيه رضايى' ه. "محمد ربانى خوراسكانى' (ه، محمدرضا علىرمايى'
}

1. كروه سلولى مولكولى و ميكروبيولوري، دانشكده علوم وفناورى هاى زيستى، دانشكاه اصفهانه اصفهان، ايران.

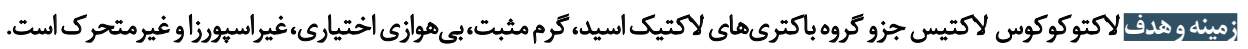

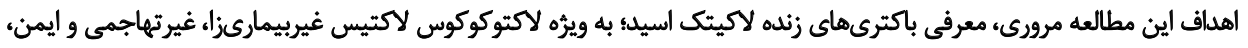

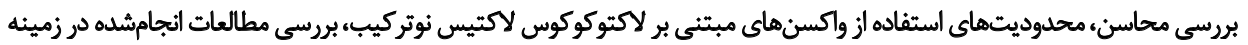

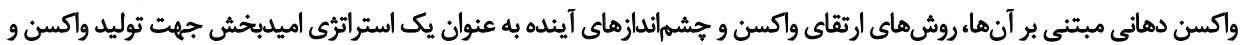

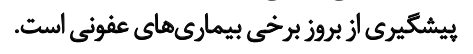

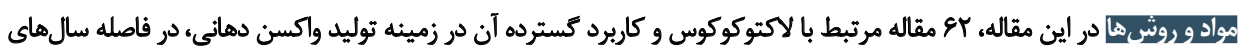

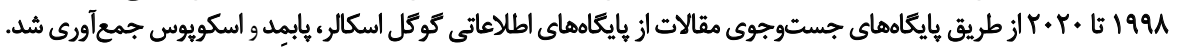

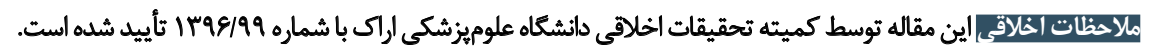

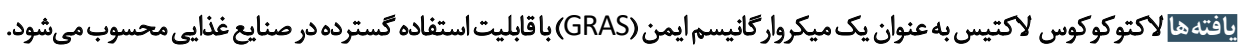

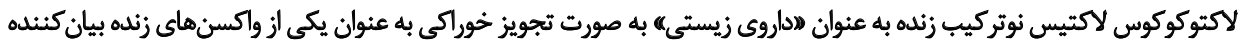

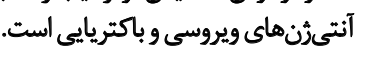

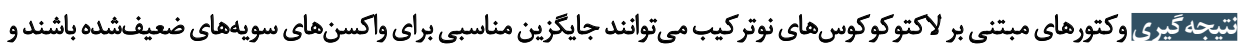

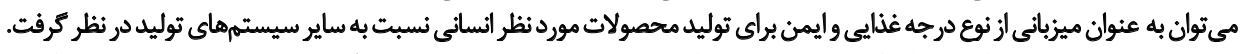

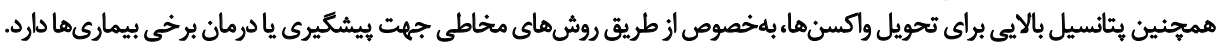

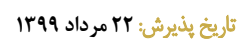

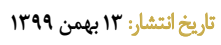

\section{كليدوازٔهها:

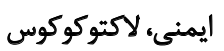

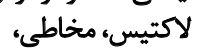 \\ واكسن}

باسيلوس آنتراسيس و بوردتلا هستند و مى توانند حامل رن مورد

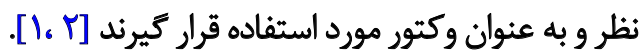

اين وكتورها (سويههاي ضعيفشده) به طور ويرهاى براي

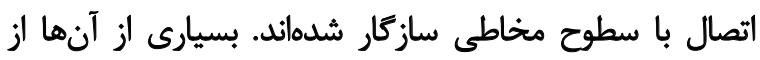

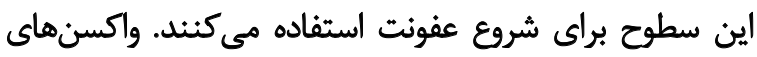

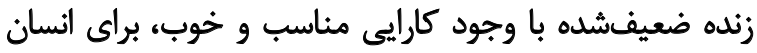

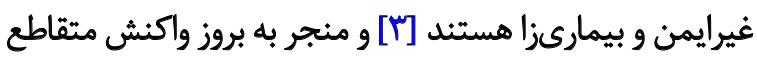

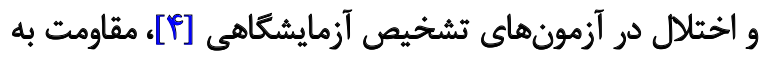

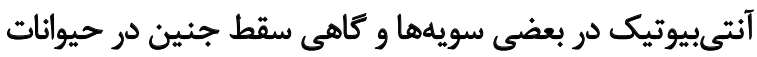

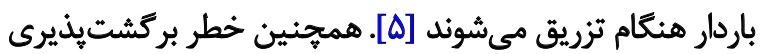

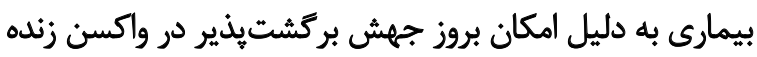
قابل انتظار است [ع]

بنابراين توجه محققان به توسعه واكسن تحت واحد جهت يافتن datês

واكسنهاي مورد استفاده جهت بيشكيرى و كنترل عوامل واكل

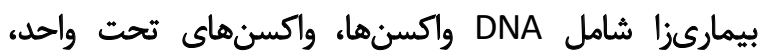

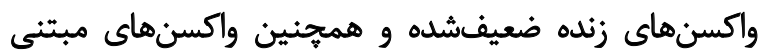

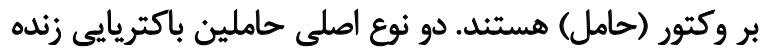

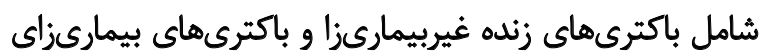

$$
\text { زنده ضعيفشده هستند. }
$$

بيشتر حاملين واكسنها، سويههاى باكترىهاى

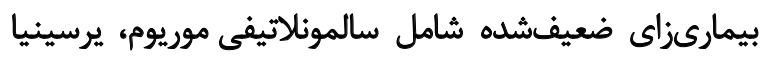

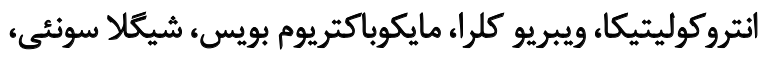

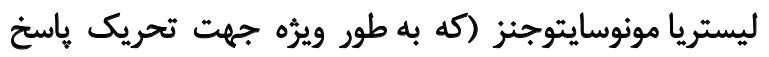
ايمنى سيتوتوكسيك محدود به MHC كلاس إناست مناسب است)،

\section{무.}

دو نويسئده مسئول:

دكتر محمد ريانى خور استعانى

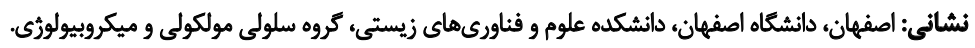
تلفن: m.rabbani@biol.ui.ac.ir بست الكترونيكي 
به عنوان مايه آغازگر توليد هينير، ماست، خميرترش نان و ديكر

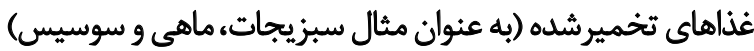

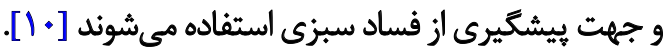

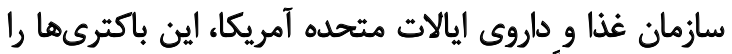

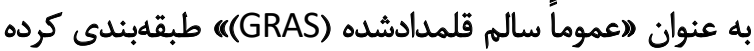

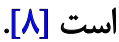

لاكتوكوكوس لاكتيس نهتنها به دليل اهميت اقتصادى، بلكه

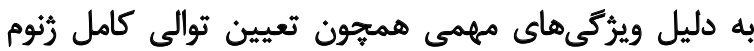

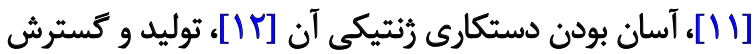

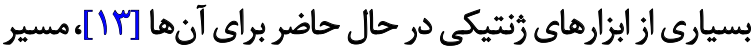

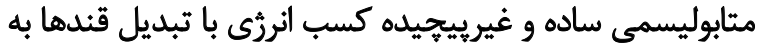

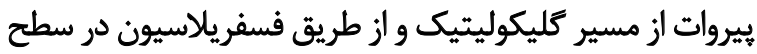

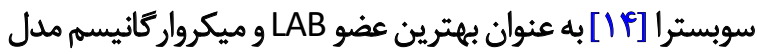
اين تروه مشخص شده است [1ه] كاربردهاى جديد و مهمى از لاكتوكوكوس غير از استفاده در

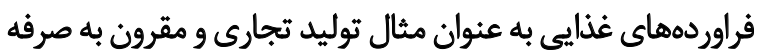

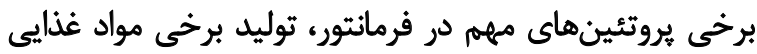

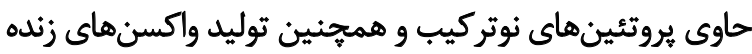

مطرح شده است [19].

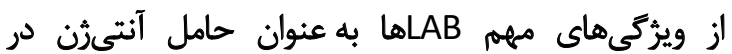

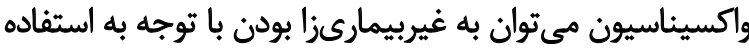

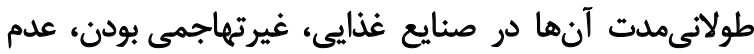

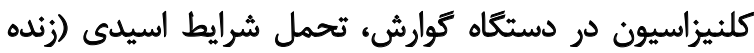

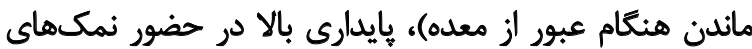

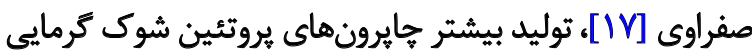
GroES و GroEL عدم وجود لييويلى Gاكاريد (اندوتوكسين) در ساختار سلولى آنها

اشاره كرد [19].

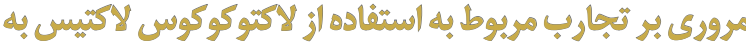

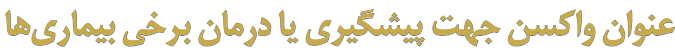

\section{درمان عفونتهاى ميكروبى نيازمند مصرف آنتى بيوتيك است.}

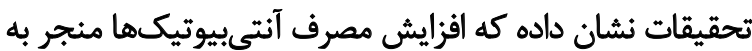

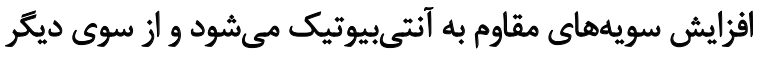

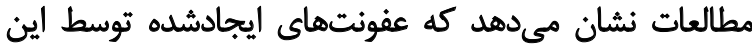

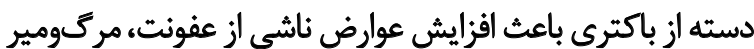

$$
\text { و هزينههاى درمان مىشود. }
$$

يكى از روشهاى كاهش مصرف آنتىبيوتيكها، استفاده

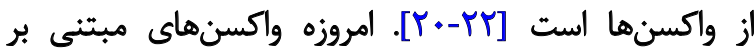

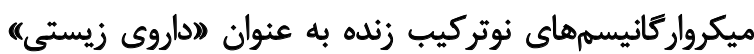

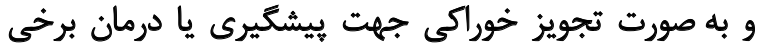

$$
\text { بيمارى بها كاربرد دارند. }
$$

كزينههاى جايكزين توليد واكسن جديد و عارى از معايب ناشى

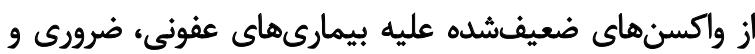

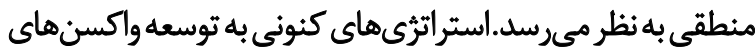

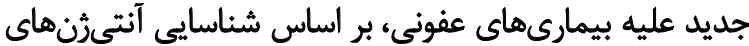

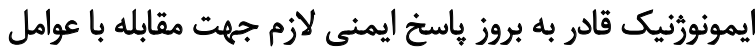

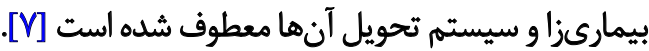
هدف از اين تحقيق، معرفي باكترى لاكتوكوكوس لاكتيس

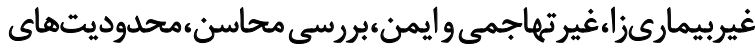

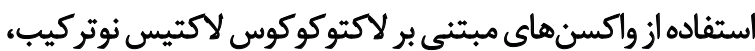

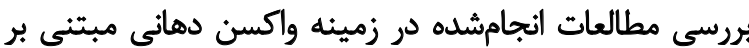

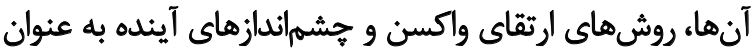

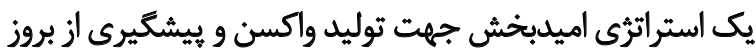
برخى بيمارىهاى عفونى است.

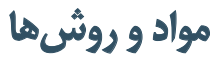

در اين تحقيق، بو مقاله مرتبط با لاكتوكوكوس و كاربرد

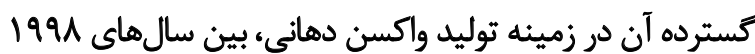

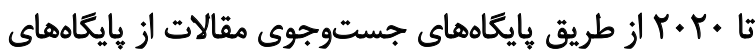

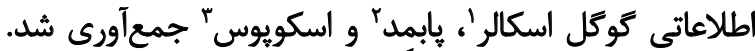

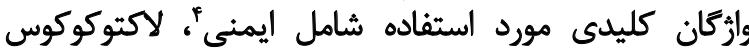

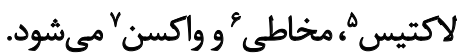

ياقتهها

\section{- الاكتوكوكوس لاكثيس}

جنس لاكتوكوكوس، كرم مثبت، بـهوازى اختيارى غيراسيورزا

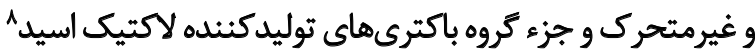

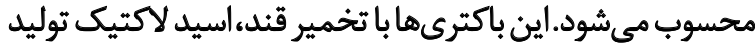

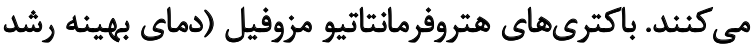

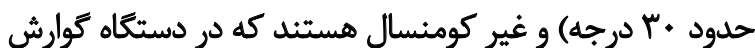

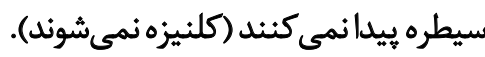
بنابراين خطر عوارض جانبى طى استفاده دهانى آنها را كارها

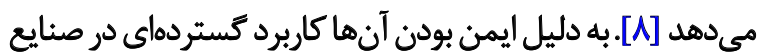

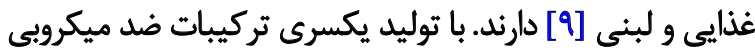

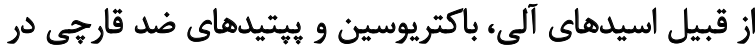

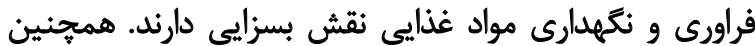

1. Google Scholar

2. PubMed

3. Scopus

4. Immunity

5. Lactococcus lactis

6. Mucosal

7. Vaccine

8. Lactic Acid Bacteria (LAB) 


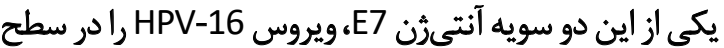

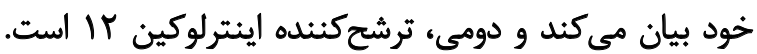

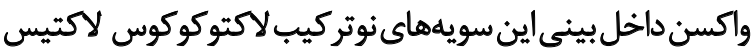

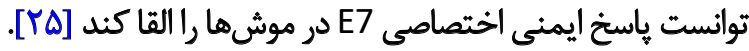

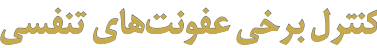

مصرف خوراكى لاكتوكوكوس لاكتيس ترشحكنينده يروتئين

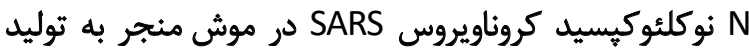

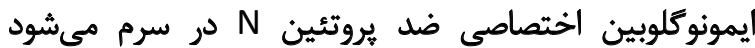

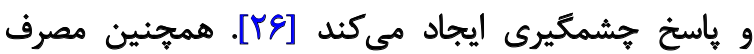

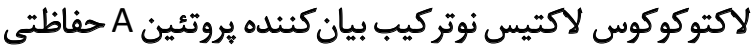

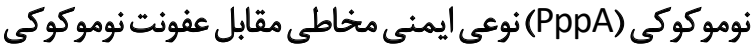

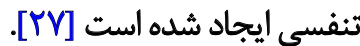

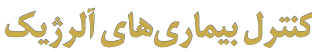

بيمارىهاى آلرزيك بيش از • ب درصد جامعه غربى رال

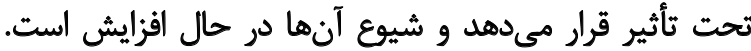

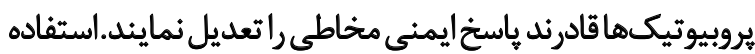

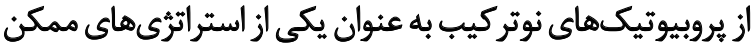

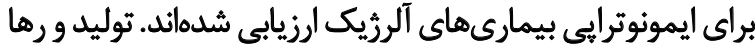

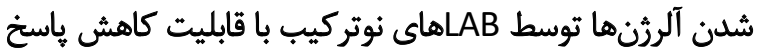

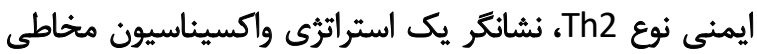

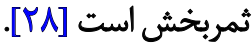

در مطالعه آدريان و همكاران، استفاده از مصرف دهانى بهاني

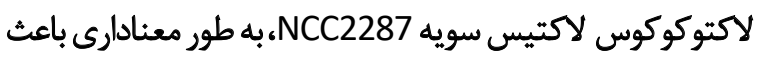

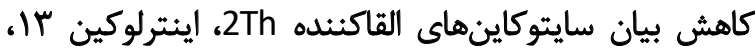

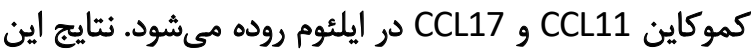

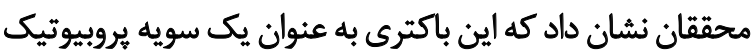

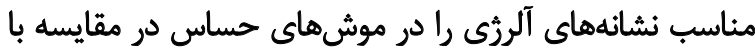

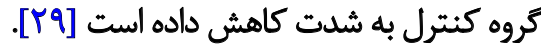

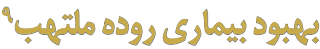

بيمارى روده ملتهب يك بيمارى مزمن است كه به دو شكل مختلف تحت عنوان كراون يا كوليت همراه با با زخم شناخ بناخته

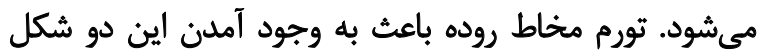

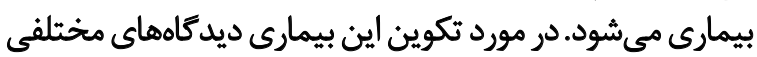

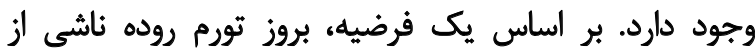

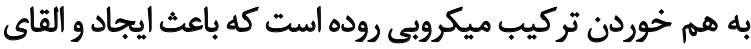
ياسخ ايمنى شديد روده و التهاب مخاطى ميكى رودود

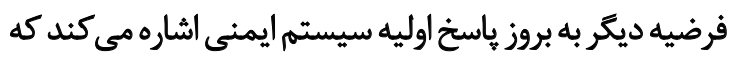

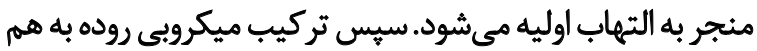

9. Inflammatory Bowel Disease (IBD)

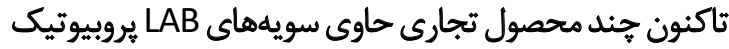

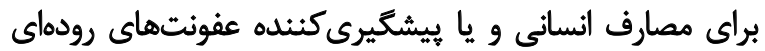

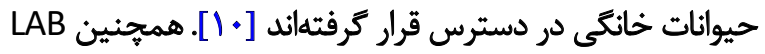

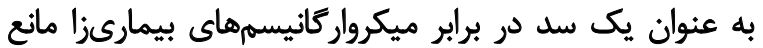

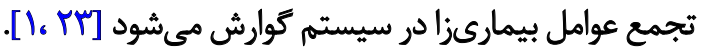

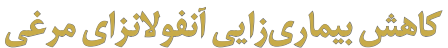

رخداد بيمارىهاى ويروسى،از جمله بيمارى آنفولاتزا به عنوان

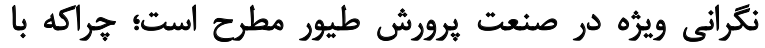

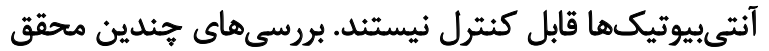

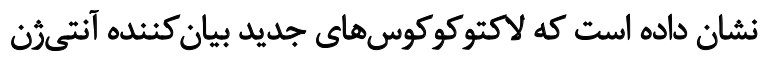

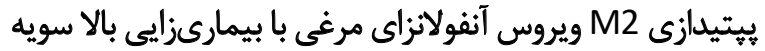

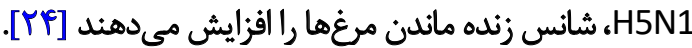
ويروتئين M2يكى از سه بروتئين ويروس آنفلوآنزاي مرغي

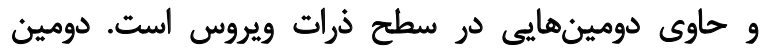

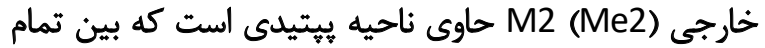

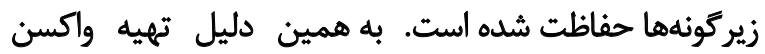

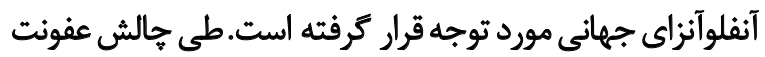

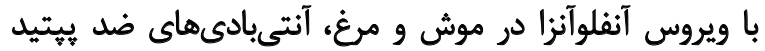

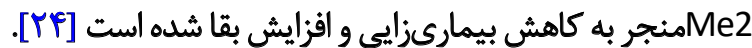

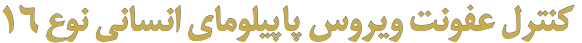

روشهاى متعددى براى واكسيناسيون ويروس HPV-16 ارائه

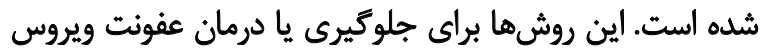

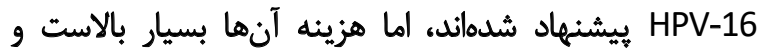

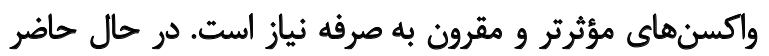

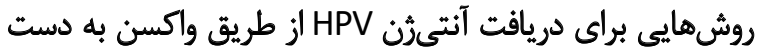

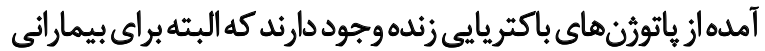

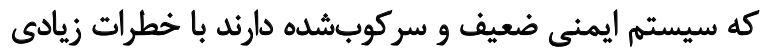

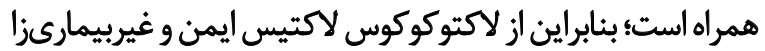

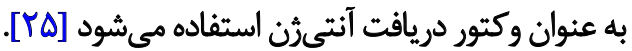
لوئيس و همكاران، به بررسى و ارزيابى اثرات محافظتى سويه

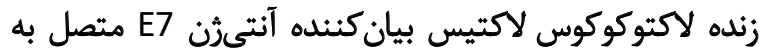

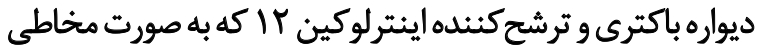

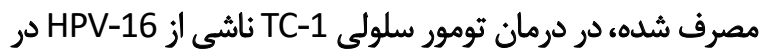

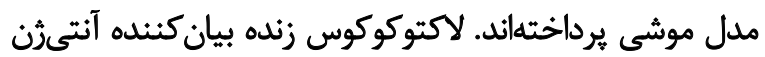

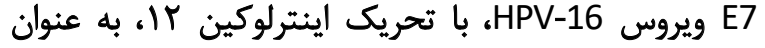

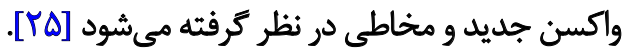
اينترلوكين Ir إيكى از سايتوكاينهاى هترودايمريك است

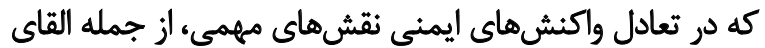

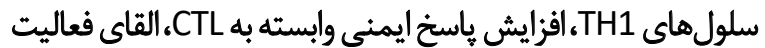

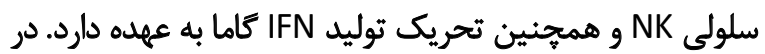
بررسى هاى قبلى دو سويه لاكتوكوكوس لاكتيس طريك تراحى شدند. 


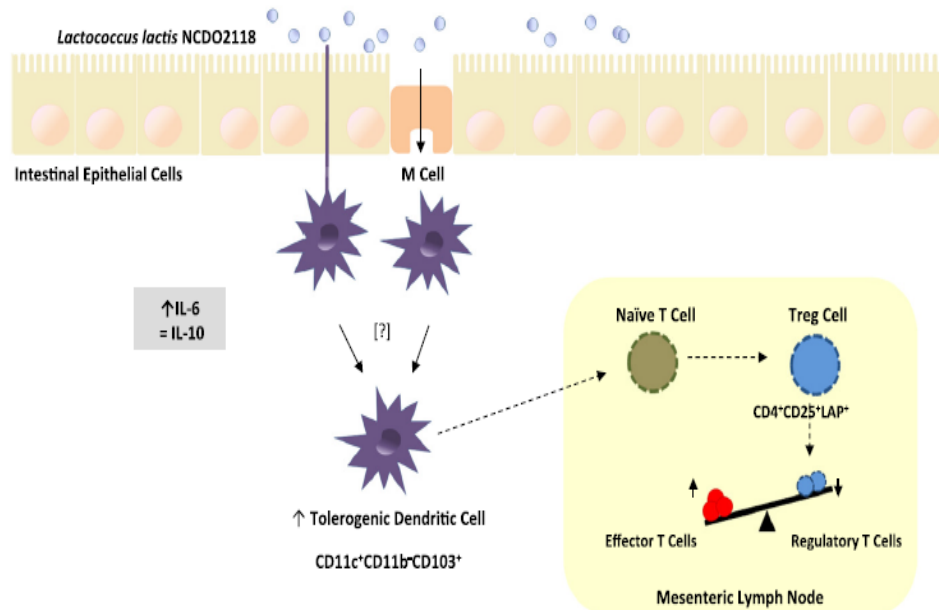

تصوير ا. مكانيسم اثر ضدالتهابى مصرف دهانى سويه لاكتوكوكوس لاكتيس NCDO2118 [ Ir]

را افزايش نمى دهد، بلكه نوع ديخرى از سلول هاى T تنظيمى كه

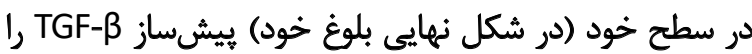

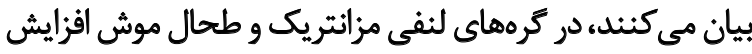

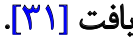

اين مطالعه يك سويه جديد يروبيوتيك راكه نقش بسرائ دائ در

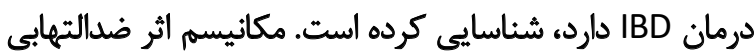

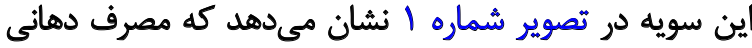

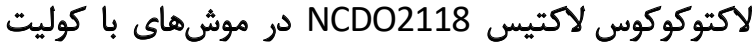

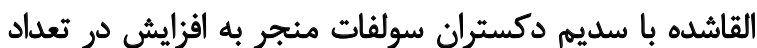
سلوهاى دندريتيك تحملزامى دشود.

سيس اين سلولها به ترههاى لنفاوى مزانتريك مهاجرت و

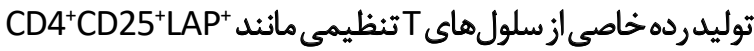

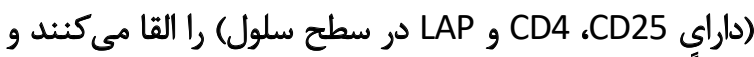

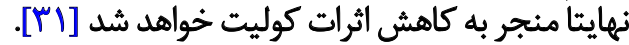
مواردى از كاربرد لاكتوكوكوس لاكتيس نوتركيب به عنوان

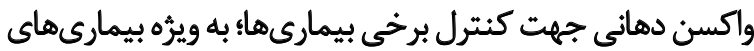

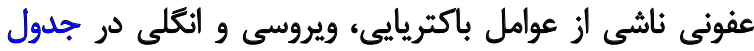

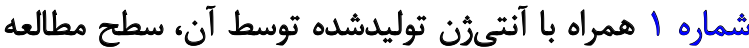

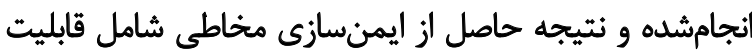

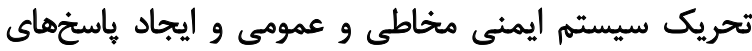
أنتىبادى IgA مخاطى ذكر شده است.

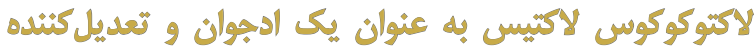

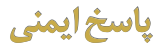

در برخى يُوهشه انه انجامشده، لاكتوكوكوس علاوه بر عرضه

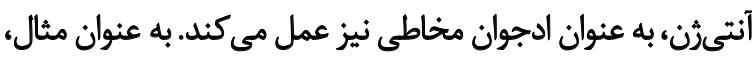

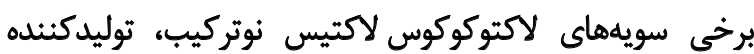

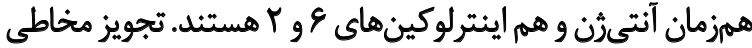
لاكتوكوكوسهاى نوتركيب، ياسخهاى ايمنى اختصاصى نسبت
خورده و پاسخ ايمنى شديدتر ايجاد مىشوده. استفاده از داروهاى

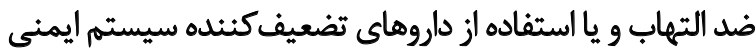

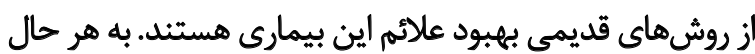

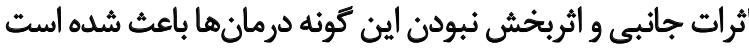

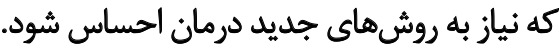
يك روش اميدواركننده جديد، استفاده از اينترلوكين

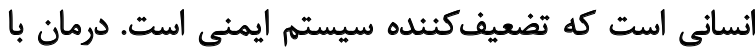

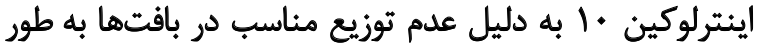

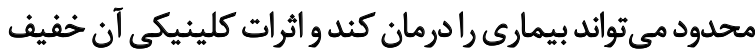

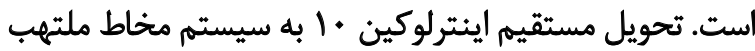
با مصرف دهاني لاكتوكوكوس لاكتيس امكانيذير است [ـ"r]. سويه جديد از لاكتوكوكوس لاكتيس كه مولكول هاي درمانكر

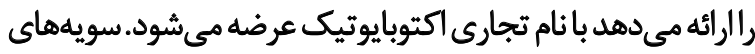

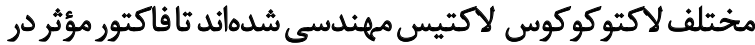

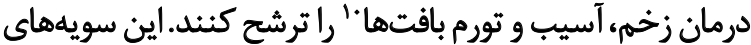

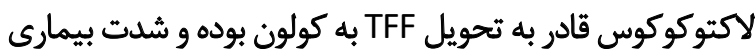

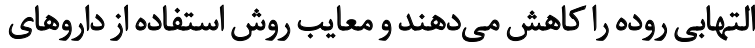

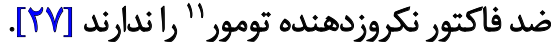
در مطالعه لورس و همكاران، مكانيسم اثر ضدالتهابى باكترى

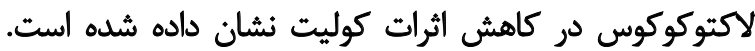

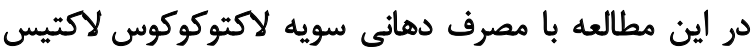

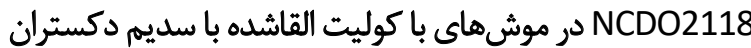

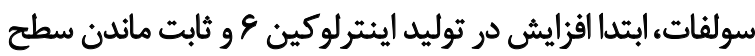

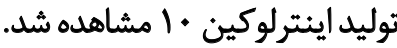

علىرغم فعاليت ضدالتهابى لاكتوكوكوس لاكتيس NCDO2118، مصرف آن فراوانى جمعيت سلولهاى T تنظيمى لآيتي

10. Trefoil Factor

11. Tumor Necrosing Factor (TNF) 
جدول ا. تجارب مربوط به استفاده از لاكتوكوكوس لاكتيس نوتركيب به عنوان واكسن دهانى

ميكرواركانيسم مورد

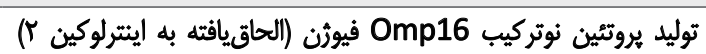

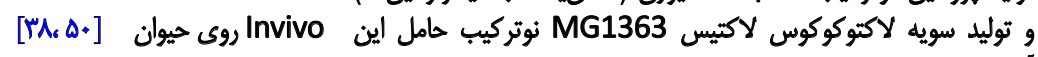

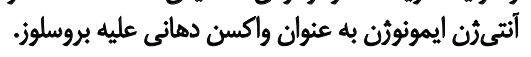

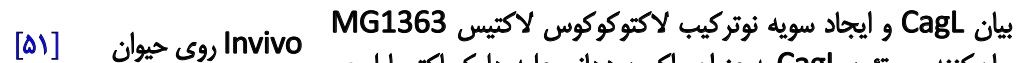

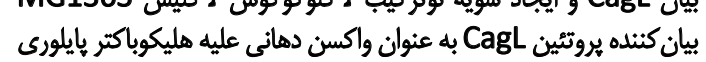

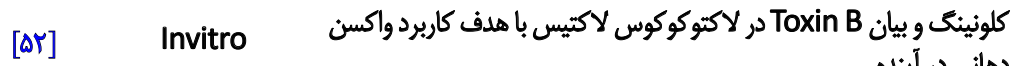
دهائي در آينده.

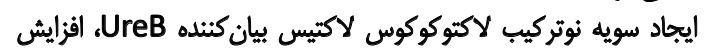

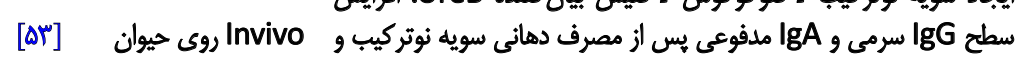

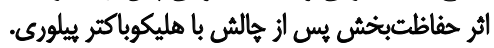

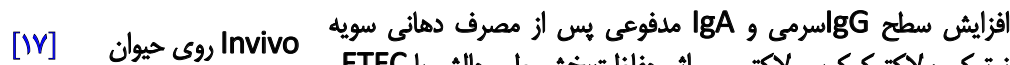

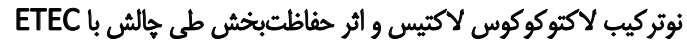

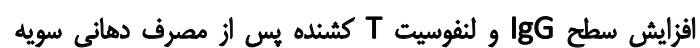

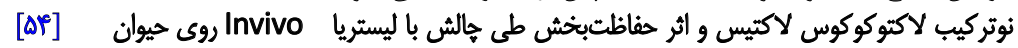
مونوسايتوجنز.

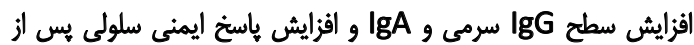

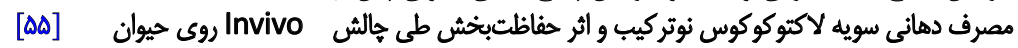
بايرسينياسودوتوبر كلوزيس.

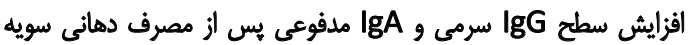

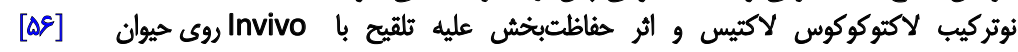
اريزييلوتريكس روزيوياتيه.

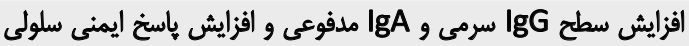

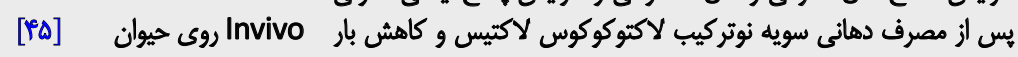

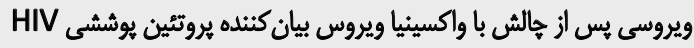

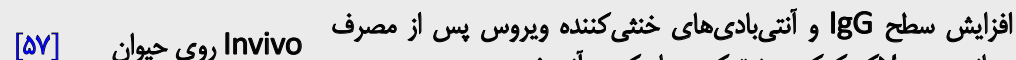

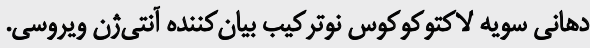

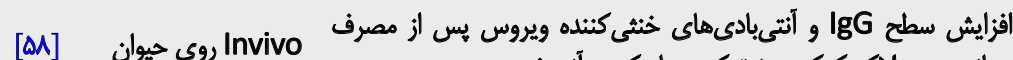

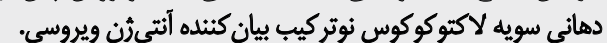

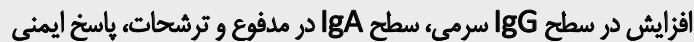

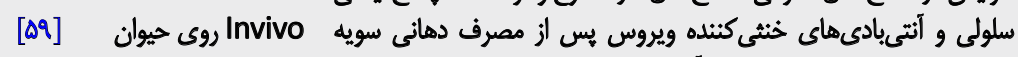

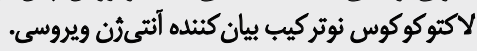

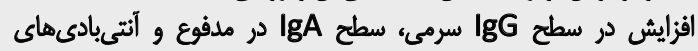

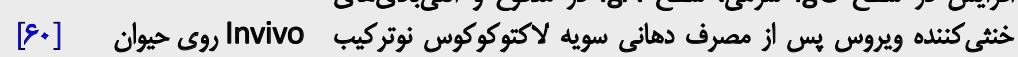

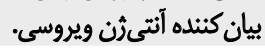

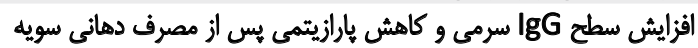

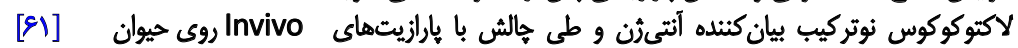

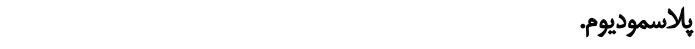

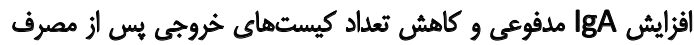

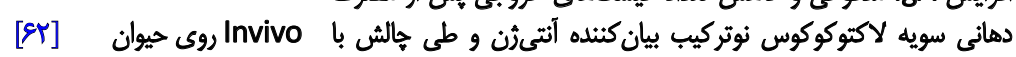
زيارديا.

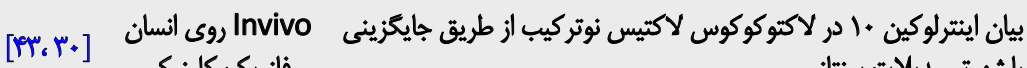

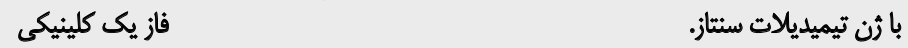

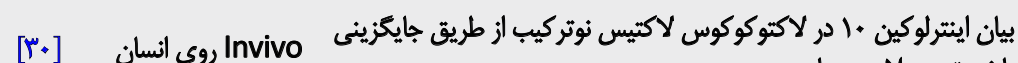
با نُن تيميديلات سنتاز.

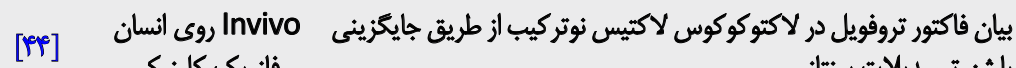
فاز يك كلينيكى انسان باثن تيميديلات سنتاز.

Omp16-IL2 بروسلا ملى تنسيس

CagL هليكوباكتر بايلورى

Toxin B كلستريديومديفيسيل

\begin{tabular}{|c|c|}
\hline UreB & هليكوباكتر هايلورى \\
\hline F4 & 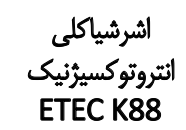 \\
\hline
\end{tabular}

ليستريامونوسايتوجنز

LcrV يرنسينياسودوتوبر كلوزيس

SpaA اريزييلوتريكس روزيوياتيه

V2-V4 Loop HIV

يروتثين يوشش

\begin{tabular}{|c|c|}
\hline EDIII & دنكو ويروس \\
\hline VPV & روتا ويروس \\
\hline VP4 & روتا ويروس \\
\hline
\end{tabular}

S protein TGEV

\begin{tabular}{|c|c|}
\hline Msp1 & مالارياى جوندكان \\
\hline CWP2 & زيارديا لامبليا \\
\hline
\end{tabular}

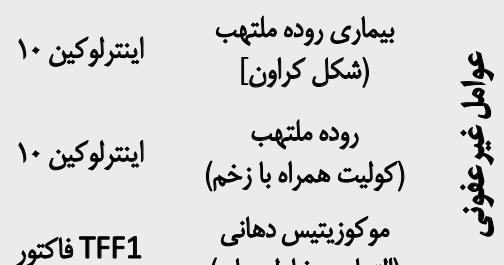
(التهاب مخاط دهان) 


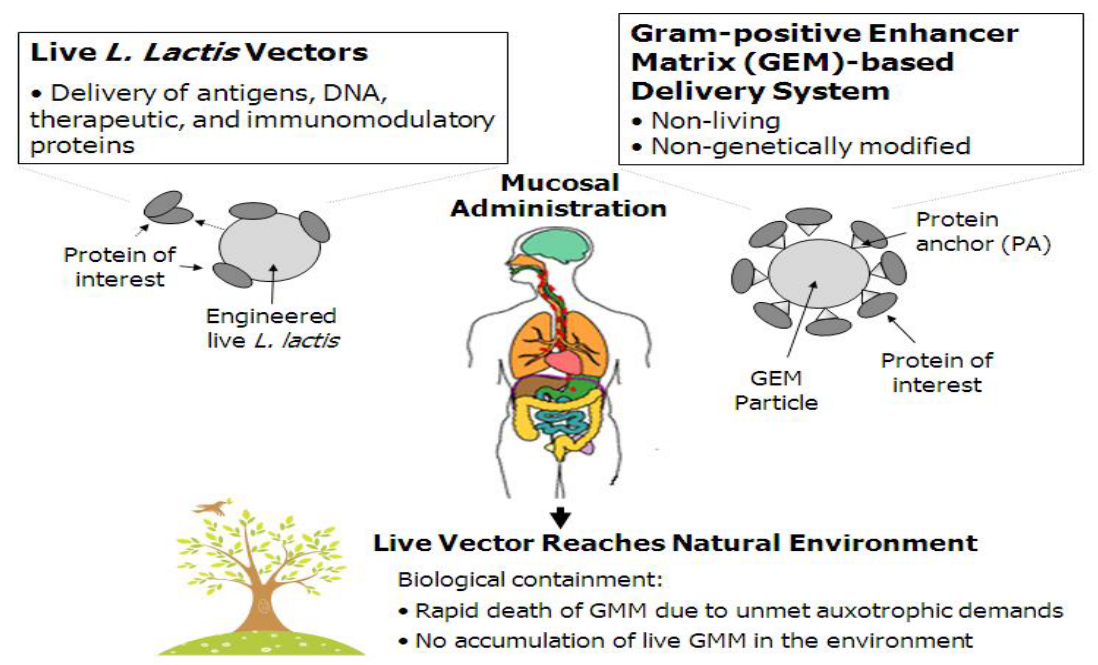

[TT] MEG تصوير T. سيستم تحويل آنتىرُنهاى يروتئين لنكر خالصشده با ذرات

سيستم تحويل آنتىثن يا تركيبات دارويى با واسطه لاكثوكوكوس

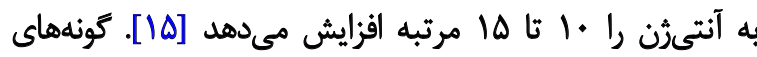

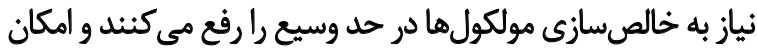

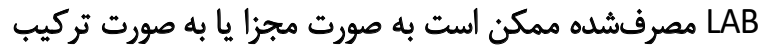

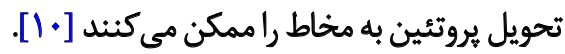

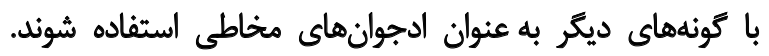

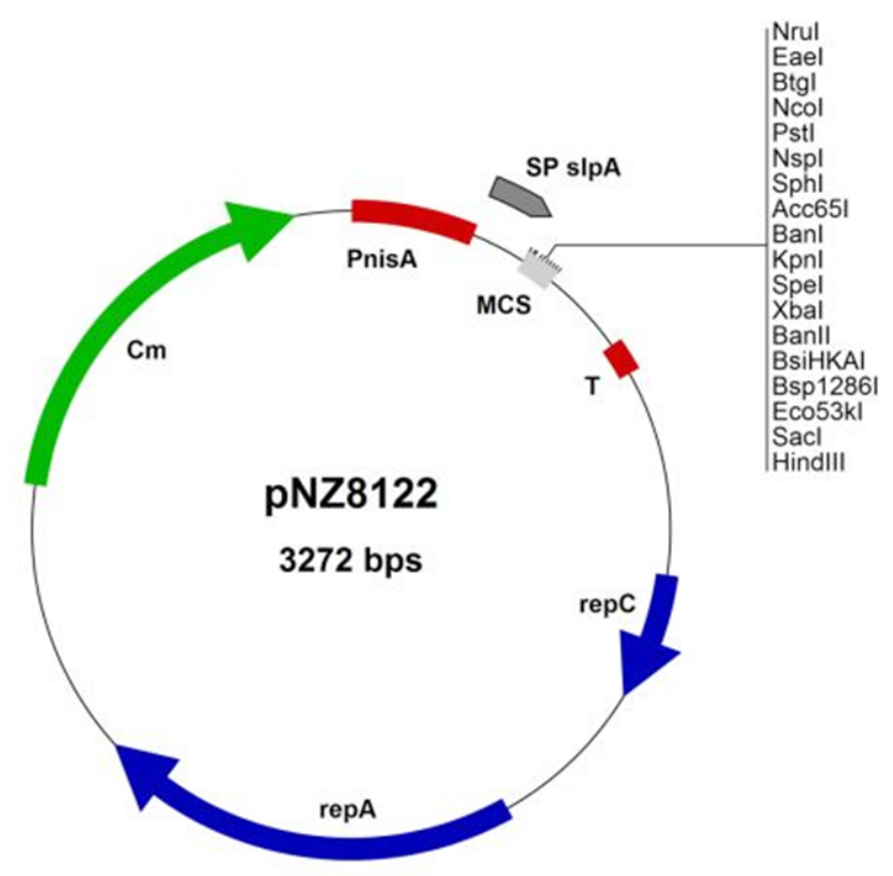

\begin{tabular}{|l|l|l|l|l|l|}
\hline & Type & Start & End & Name & Description \\
\hline & Promoter & 3 & 203 & PnisA & nisin A promoter region \\
\hline & Region & 204 & 296 & SP slpA & Signal sequence of s/pA gene \\
\hline Region & 297 & 352 & MCS & Multiple Cloning Site \\
\hline & Terminator & 498 & 550 & T & Termination sequence of pepN gene \\
\hline Gene & 893 & 1102 & repC & Replication gene $C$ \\
\hline & Gene & 1371 & 2069 & repA & Replication gene $A$ \\
\hline $\begin{array}{l}\text { Selectable } \\
\text { Marker }\end{array}$ & 2529 & 3179 & Cm (cat) & Chloramphenicol resistance \\
\hline
\end{tabular}

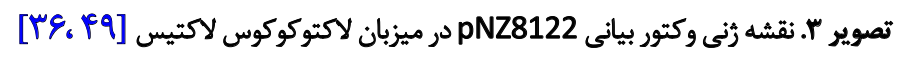




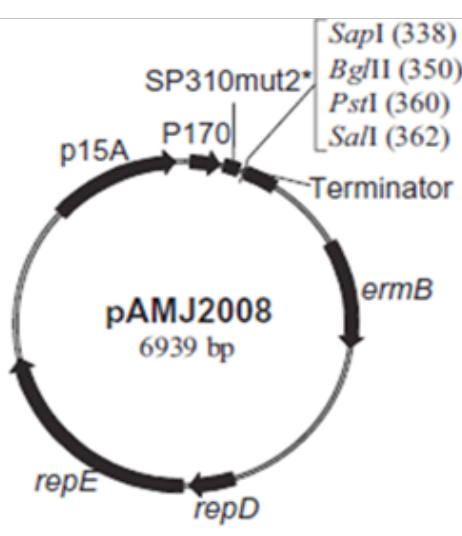

ती

تصوير †. نقشه رثنى وكتور بياني 2008 [بان اكتيس سويه

ضمن ذرات GEM فعاليت ادجوانت ذاتي دارند كه هاسخ ايمنى

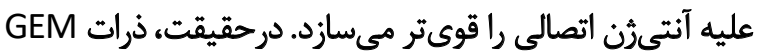

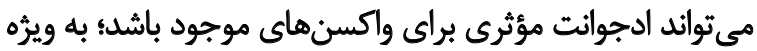

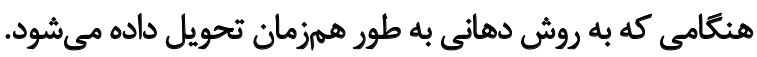
علاوه بر اين، سيستم مبتني بر GEM هي ثواند براى هر دو نوع

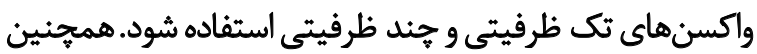

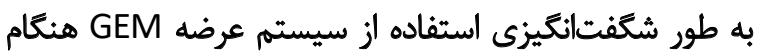

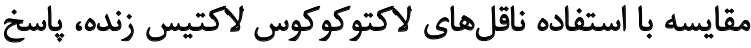

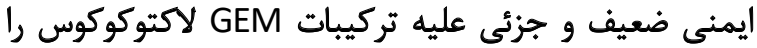

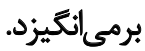

به طور كلى سيستم نمايش GEM، روش جديدى جهت استفاده از واكسنهاى غير زنده و بدون اصلاح رثنتيكى با الدجوان

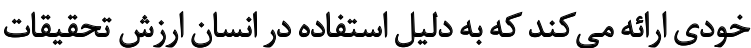

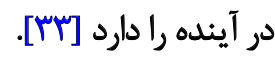

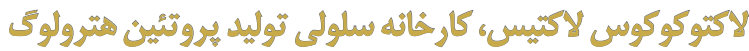

تلاشهاى زيادى از سه دهه اخير براي مطالعه و شُناخت

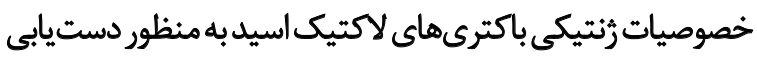
به محصولات صنعتى بهتر انجام شده است. امروزه لاكتوكوكوس لاستئي

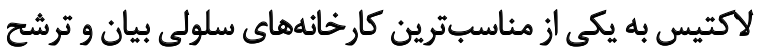

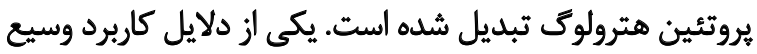

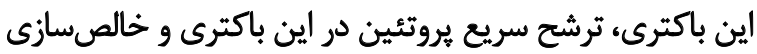

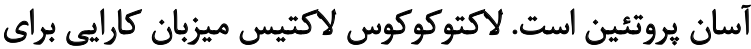

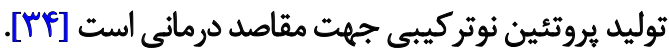

در دوره اخير شناخت وسيع در زمينه رُنتيك منجر به توسعه

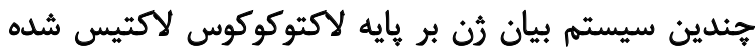

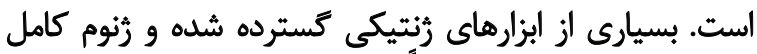

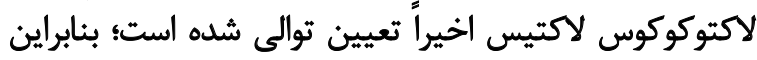

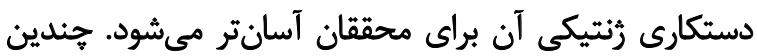

كاربرد يك سويه لاكتوكوكوس لاكتيس نوتركيب بيان كنينه

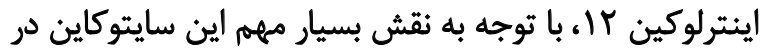

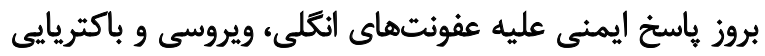

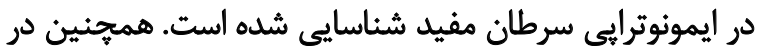

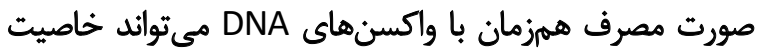
ادجوان داشته باشد. اثمرف

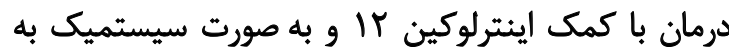
دليل سميت بالا با محدوديت روبهروستء اما بيان القايتي و ترشيح

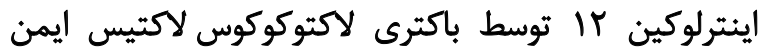

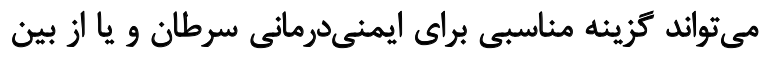
بردن بيمارىهاى عفونى باشد.

مطالعه مين نُشان داد لاكتوكوكها به دليل آزاد شدن

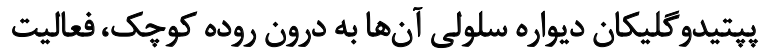

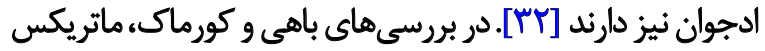

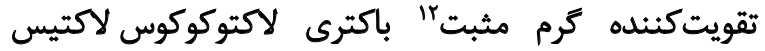

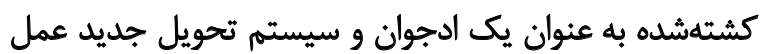
كرده و توسط محققان به طور كسترده استفاده شده است. طي بررسي هاي انجامشده، لاكتوكوكوس لاكتيس غيرزنده و اصلاح زئتيكى نشده تحث تيمار اسيدى قرار كرفته و منجر به تشكيل ذرات لاكتوكوكوس لاكتيس كشتهشده تحت تحت عنوان

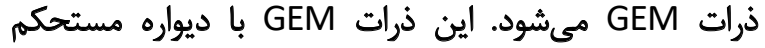

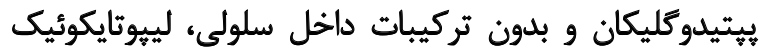

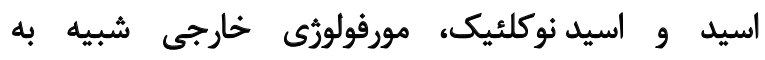
لاكتوكوكوس لاكتيس از خود نشان مي دهند. آنتىثنهاى هدف در ميزبان بيانى لاكتوكوكوس لاكتيس

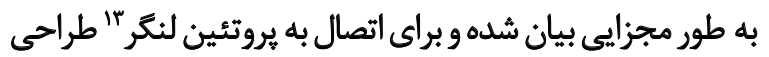

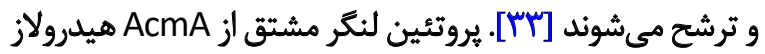

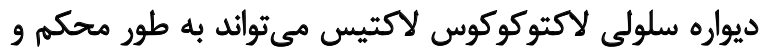

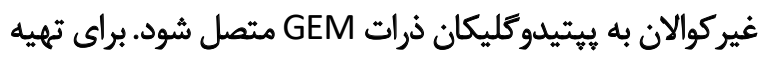

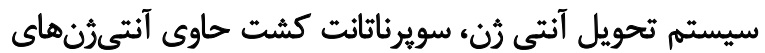

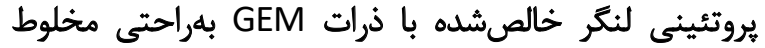
مي شيود [MTH].

سيستم تحويل آنتىرنهاي بيروتئين لنكر خالصشده با

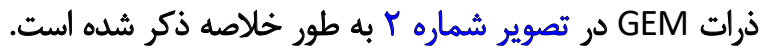

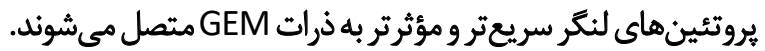

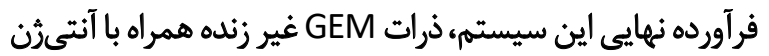

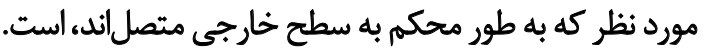
از مزيتهاي قابل توجه اين روش، عدم وجود يك اركانيسم

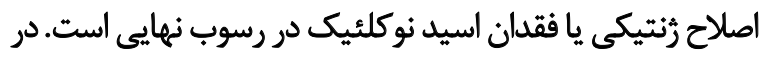

12. Gram-Positive Enhancer Matrix (GEM)

13. Protein anchor 


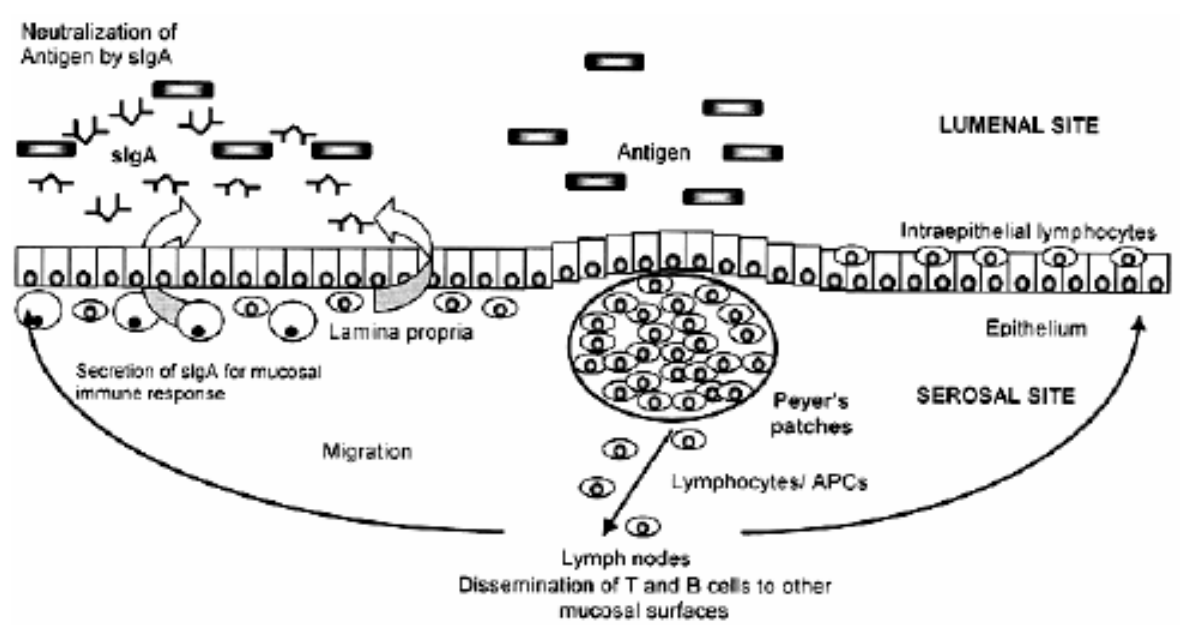

تصوير هـ. القاى ياسخ ايمنى مخاطى طى استفادها ازو واكن خوراكى

ثن هاى همولوك و هترولوك در باكترىهاى كرم مثبت توسعه

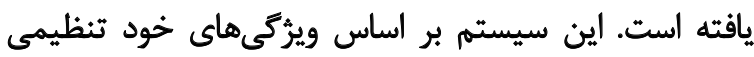

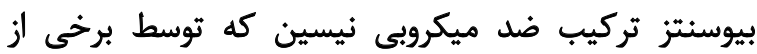

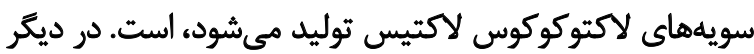

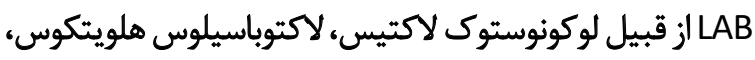

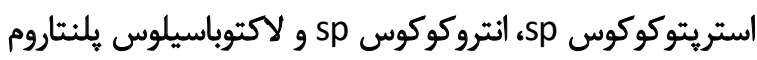
بررسى شده كه نشان از تنوع اين سيستم است.

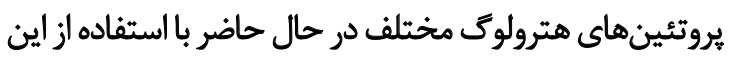

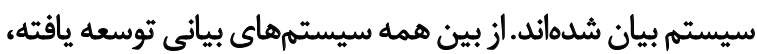

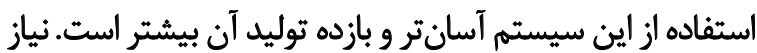

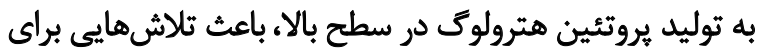
بهتر كردن سيستم NICE شده است.

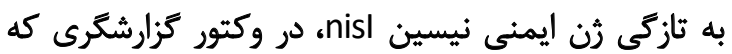

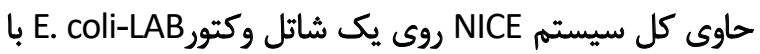

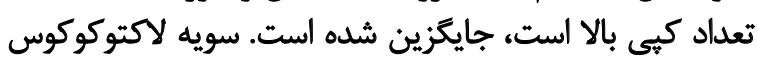

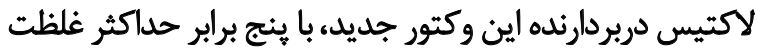

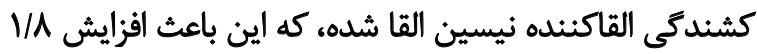

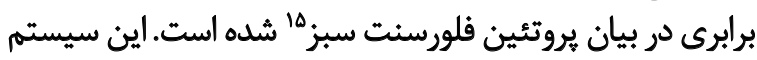

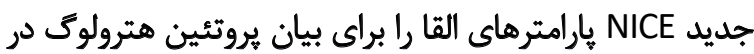

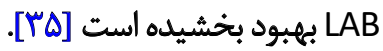
به عنوان مثال، وكتور pNZ8122 جهت توليد يروتئين در لاكتوكوكوس لاكتيس سويه NZ9000 و و با استفاده از سيستم بروني

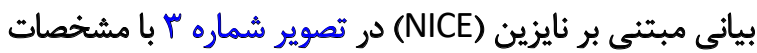

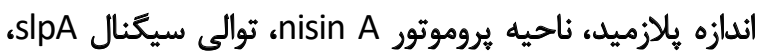

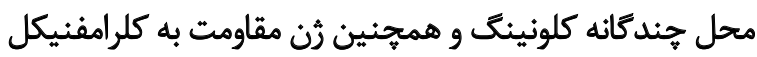

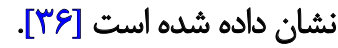

جندين بروموتور لاكتوكوكوس تنظيمشده با شرايط محيطى
يروتئين هترولوك توليدشده توسط لاكتوكوكوس لاكتيس

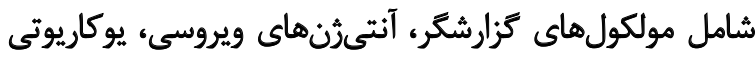

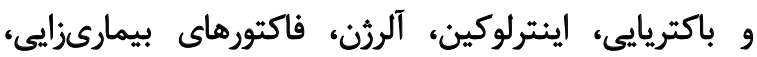

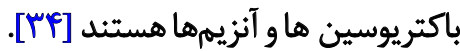

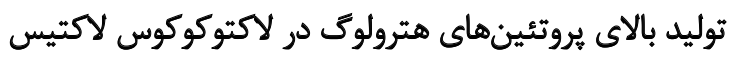

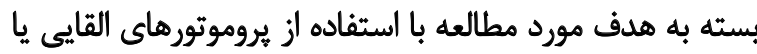

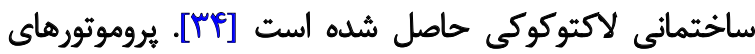

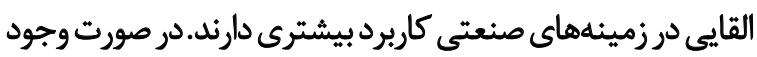

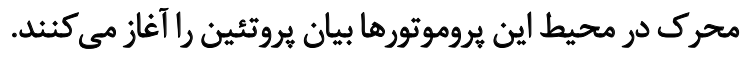

جندين يروموتور لاكتوكوكوس لاكتيس شناختهشده از

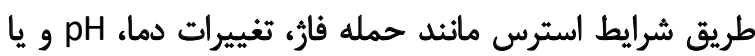

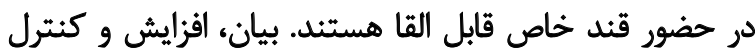

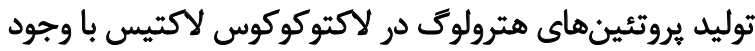

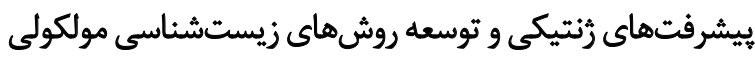
تسهيل شده است [1]

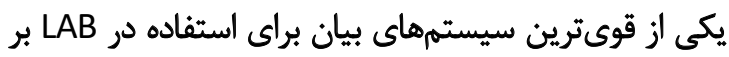

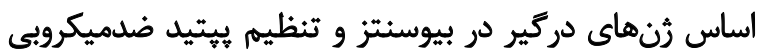

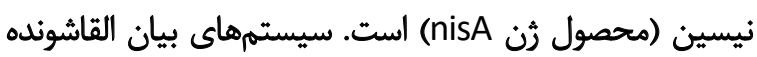
توسط نيسين توسعه بيدا كردهاند.

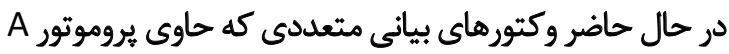

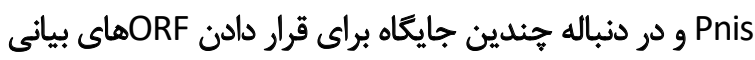

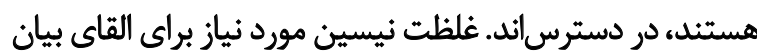

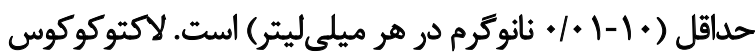

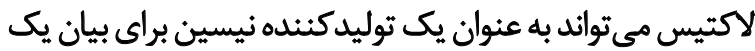

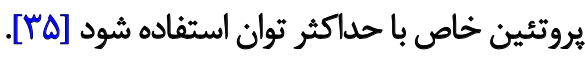

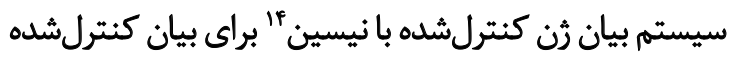

14. Nisin Controlled Gene Expression System (NICE) 
زنده بمانند، اما به مخاط كوارش حمله نمى كنيند و كولونيزاسيون

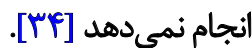

بيشتر واكسنهاى مورد استفاده تزريقىاند؛ بنابراين جهت

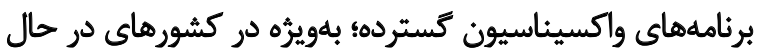

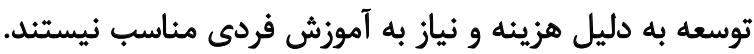

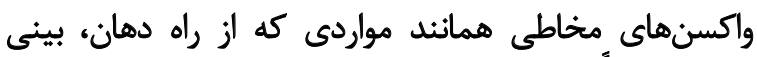

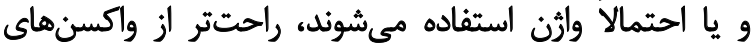

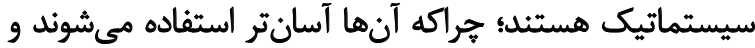
توليد آنها به نسبت ارزانتر است.

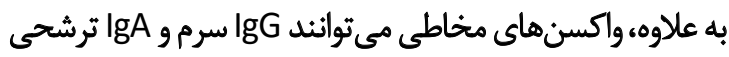

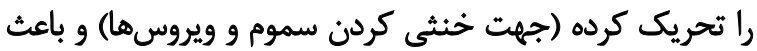

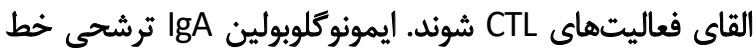

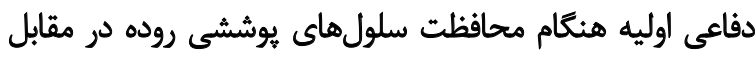

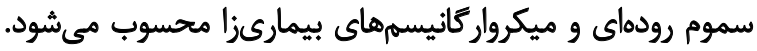

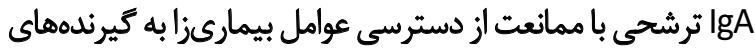

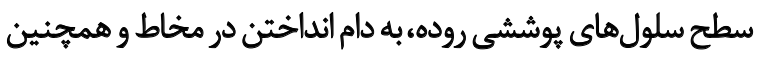

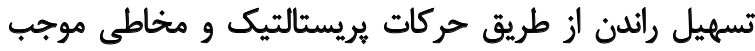

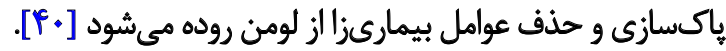

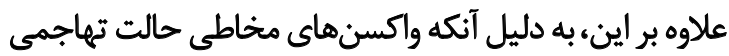

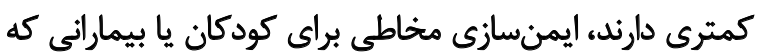

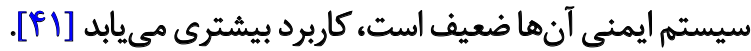

بحث

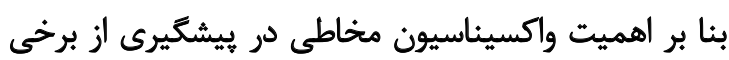

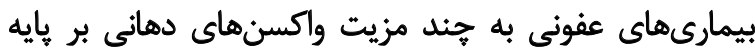

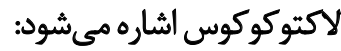

1. استفاده كسترده اين باكترى در صنايع غذايى، لبنى و و

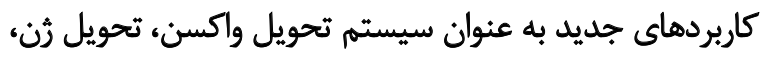

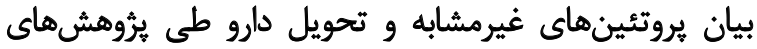

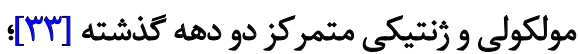
r. فقدان اندوتوكسين و ليهيو يلى ساكاريدهاى باكترىهاى

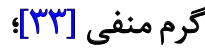

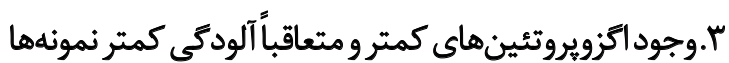

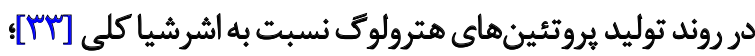
خأ. توانايى تحريك باسخهاي ايمنى به دليل وجود تركيبات

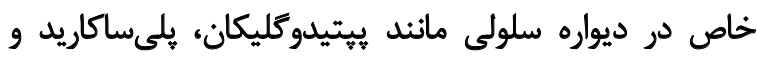

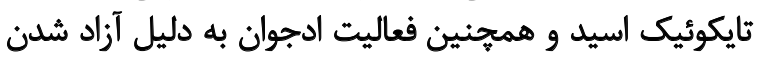

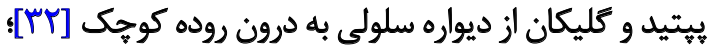
ه. غيرتهاجمى و غيرانكلى بودن و يتانسيل كمتر جهت إيجاد

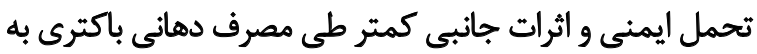

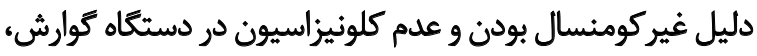

جداسازى شدهاند. از بين آنها • PIV يك يروموتور قوى است

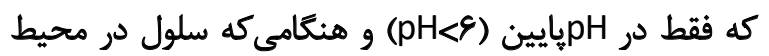

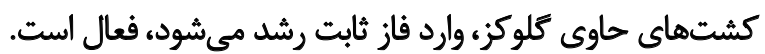

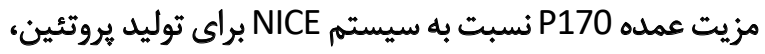

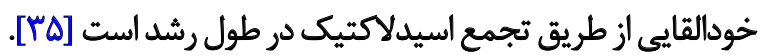
همجنجين يكى از وكتورهاى مورد استفاده در ميزبان لاكتوكوكوس لاكتيس سويه

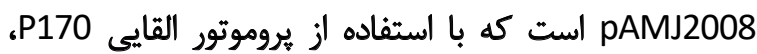

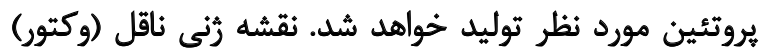

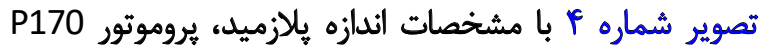

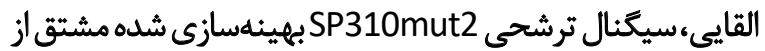
توالى سيكنال SP310 لاكتوكوكوس لاكتيس با شمارئين

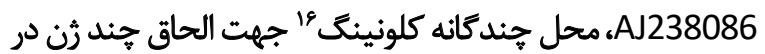

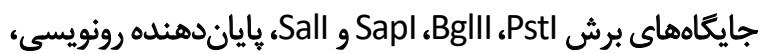

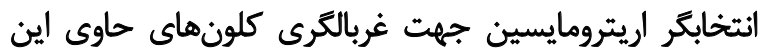

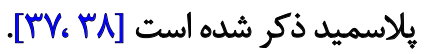

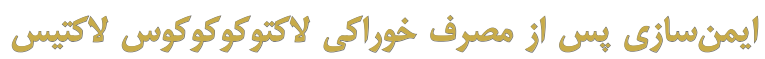

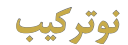

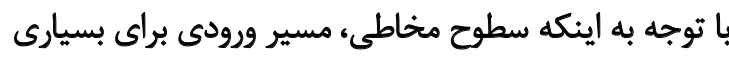

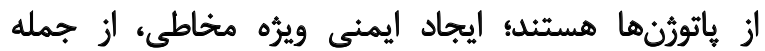

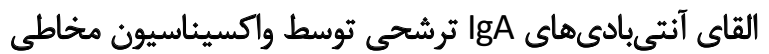

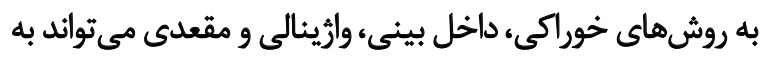
حذف زودهنكام و كارآمد عفونت كمك كندي

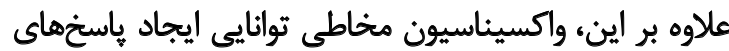

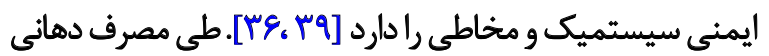

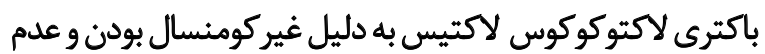

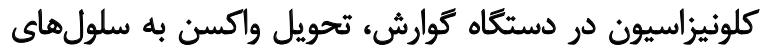

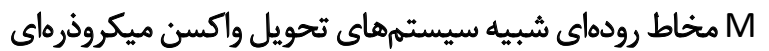

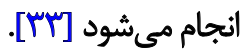
با توجه به تصوير شماره ه، طى استفاده دهانى اين واكسن،

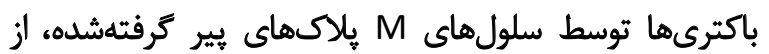

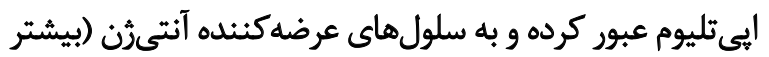

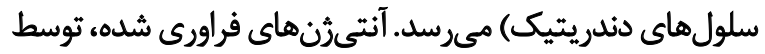

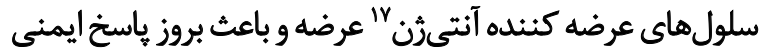

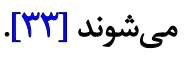

مصرف دهانى آن نسبت به ميكرواركانيسمهاى تخفيف

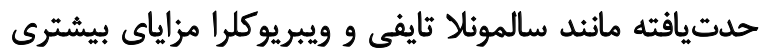

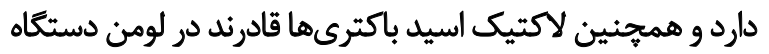

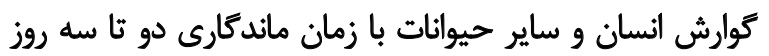

16. Multiple cloning site

17. Antigen Presenting Cell (APC) 
شناسايى، خلوص، يايدارى و ايمن بودن محصول دارويى است.

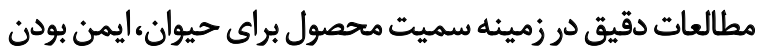

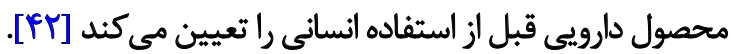
به منظور رفع خطر ناشى از انتشار سويههاى اصلاح رنتيكى

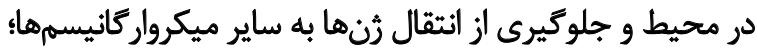

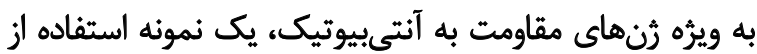

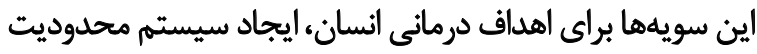

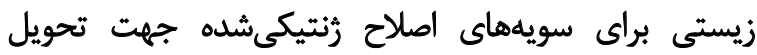
اينترلوكين · إبه روده است.

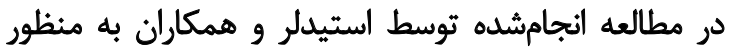

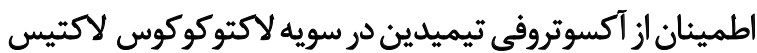

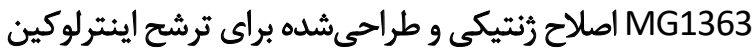

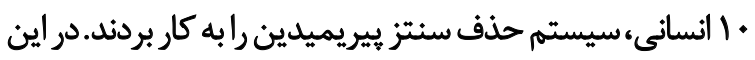

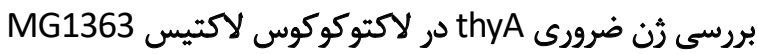

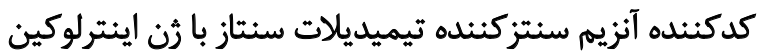

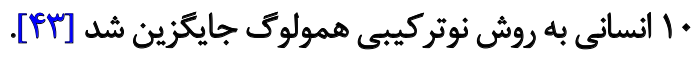

در اين مطالعه سويه أكسوتروف حاصل، فاقد نشانكر

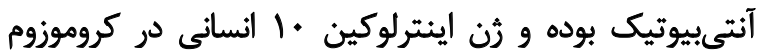

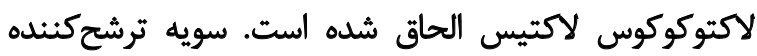

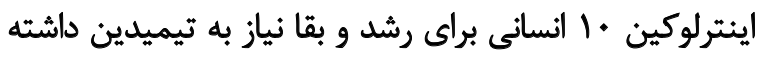

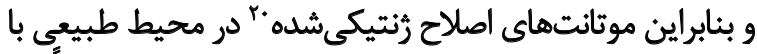

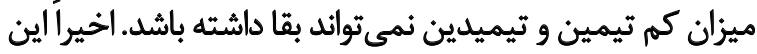

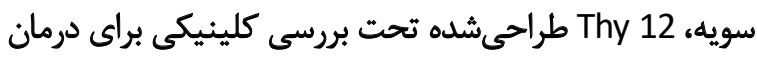

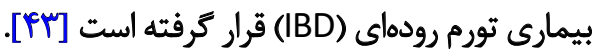

كرجه مرك باكترىهابه دليل فقدان تيمين در خيلى از مقالهها

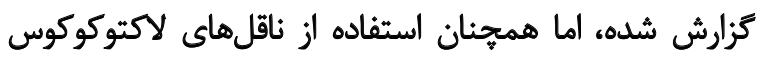

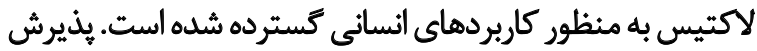

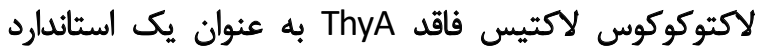

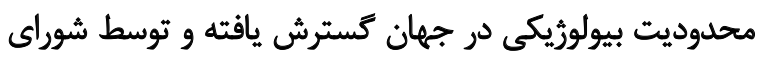

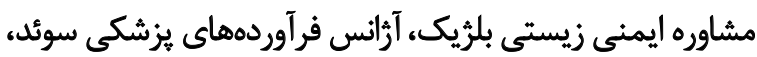
آرانس حفاظت محيطى كانادا تصويب شده است. طى بررسى هاى ديكر محققان، از سيستم محدوديت زيستى لإئى

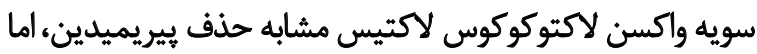

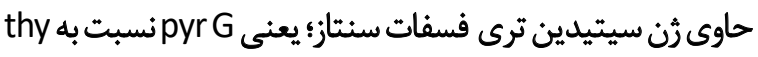

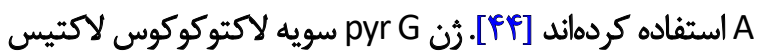

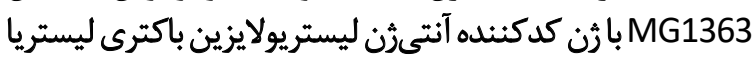

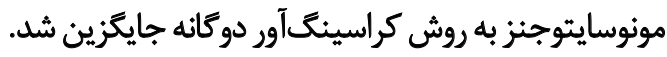
سويه آكسوتروف حاصل به عنوان يك واكسن القاكنيده ياسخ

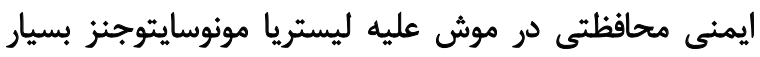

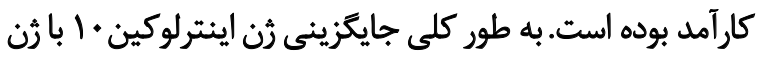

20. Genetically Modified Microorganisms (GMM)
تحويل واكسن به سلول هاى M مخاط رودهاى شبيه سيستمهاى تحويل واكسن ميكروذراي [بrاى].

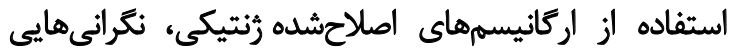

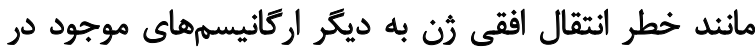

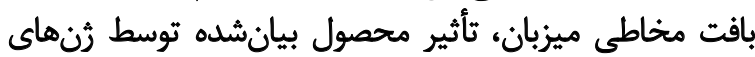

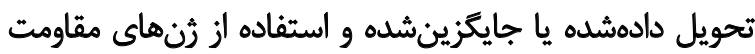

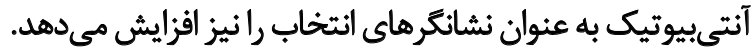

لاكتوكوكوس لاكتيس به عنوان واكسن زنده بايد جايد جندين

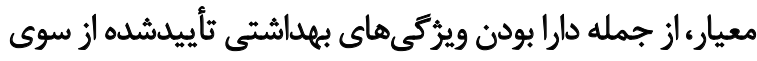

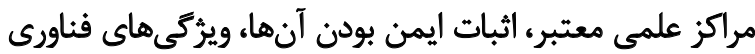

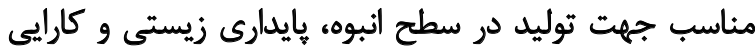

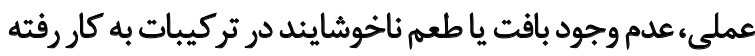

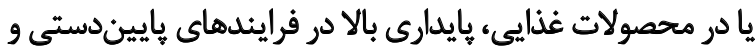

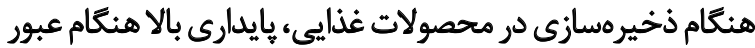

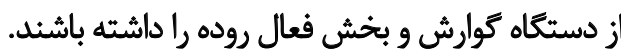

با توجه به رويكرد جديد مبنى بر استفاده از لاكتوكوكوس

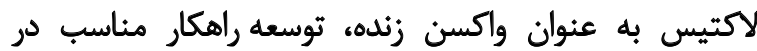

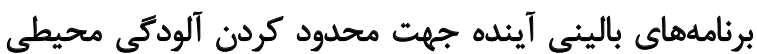

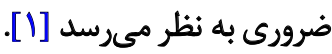

استفاده از وكتورهاى زنده محدوديتهاى زيستى به همراه

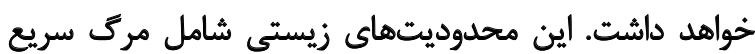

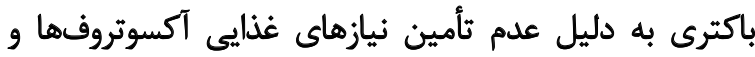

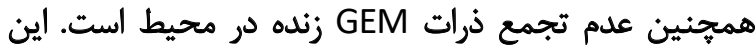

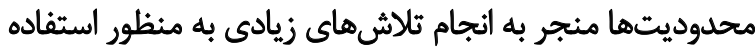

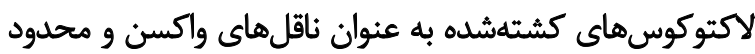

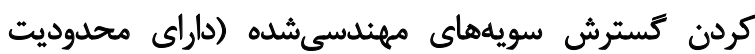
زيستى) در محيط شده است [Tست].

مطالعه خيلى دقيق شيميايى، ساخت و كنترل محصولات

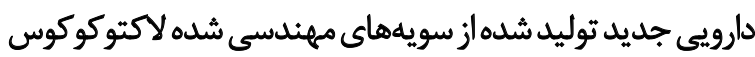

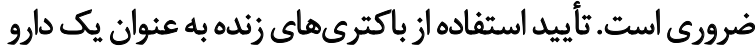

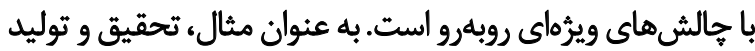

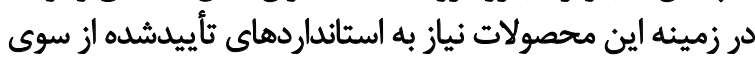

$$
\text { صنايع داروسازي دارد. }
$$

دستورالعمل هاى منتشرشده از سوى كنفراسهاي بينالمللى

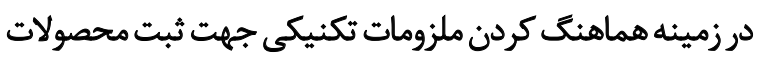

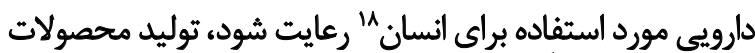

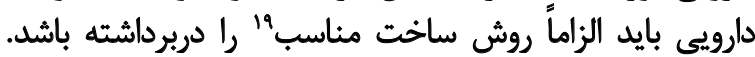

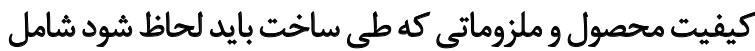

18.The International Council for Harmonisation of Technical Requirements for Pharmaceuticals for Human Use (ICH)

19. Good manufacturing practice (GMP) 
ليستريا مونوسايتوجنز ارتقا يافت [بس]. اين سويه لاكتوكوكوس

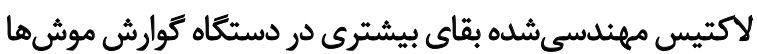
هنكام مقايسه با سويه وحشى نشان بيشن داد.

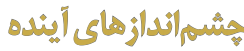

از جمله اهداف بيشرور، كسترش دادن ناقل واكسن لاكتوكوكى

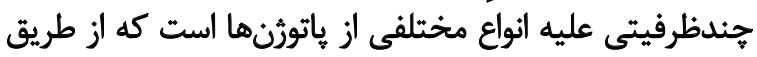

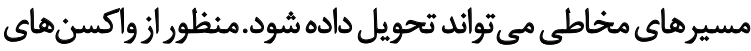

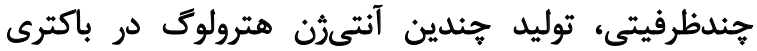

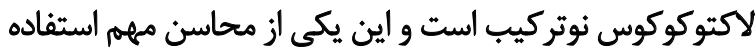

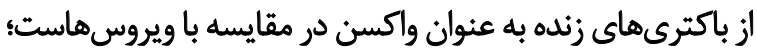

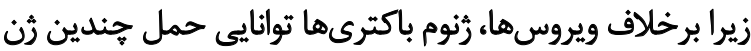

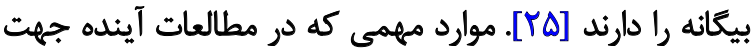

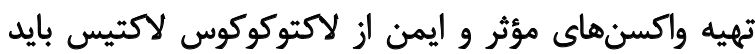
ملاحظه شود، شامل موارد ذيل هستيند:

- حذف رُنهاى ضرورى و استفاده از سويههاى اكزوتروف با

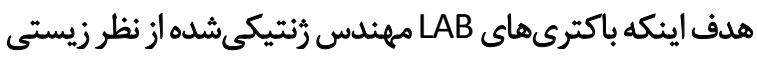

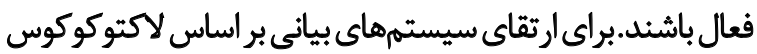
لاكتيس از سيستمهاى القايى استفاده شود.

- افزرايش ياسخ ايمنى با هدف ميرى آنتىرثنهاي داخل سلولى

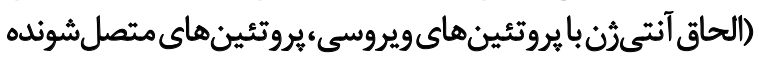

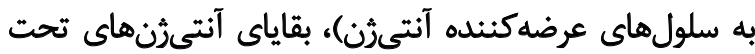

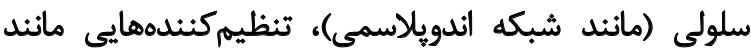
اينترلوكين و يروتئينهاى شوك حرارتى و ويروسى. تنئي

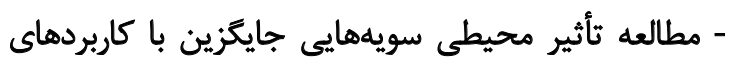

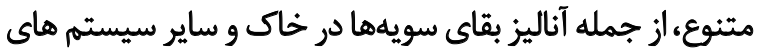
محيطى. (متئ. - فرايش بيان يروتئين با بهينهسازي كدون براي لاكتوكوكوس،

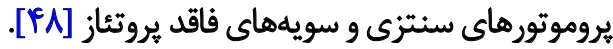
نتيجهئيرى

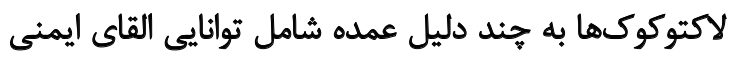

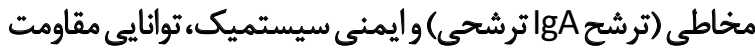

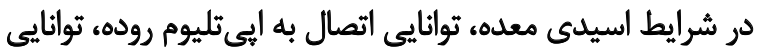

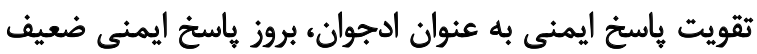

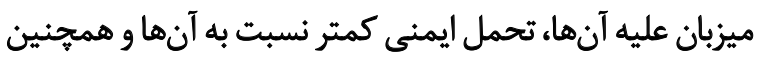

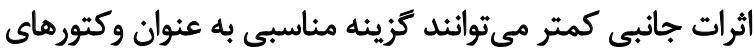

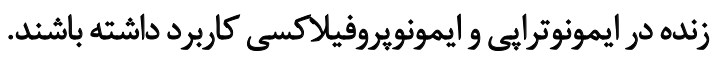

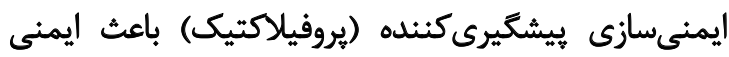

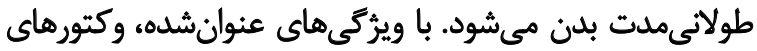

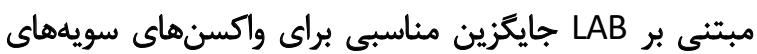

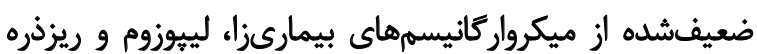

تيميديلات باكترى لاكتوكوكوس لاكتيس منجر به ايجاد سويهاى

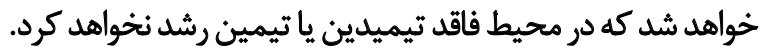
اين سويه فاقد ثن تيميديلات (سويه فاقد Thy A و و به به دليل

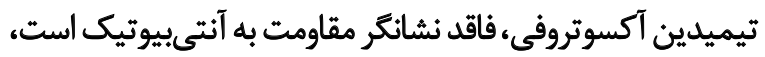

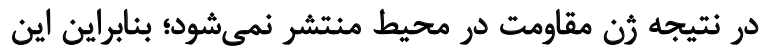

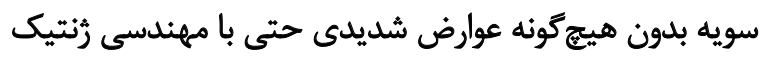

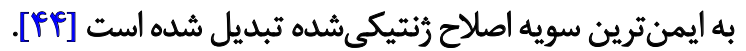
برخى روشهاى ارتقاى تحويل واكسن دهانى شامل تحويل

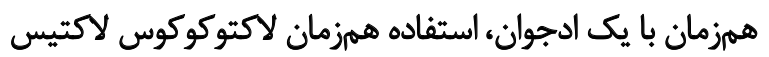

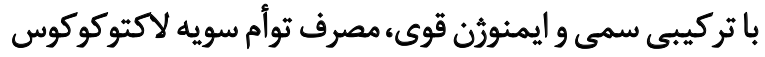

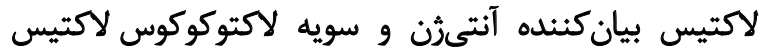
بيان كنيدها ينتر لوكين هستيند. بقاى لاكتوكوكوس لاكتيس و آنتىثن همراه آن تحت تأثير

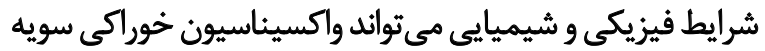

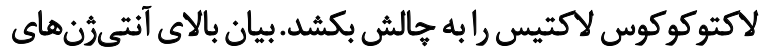

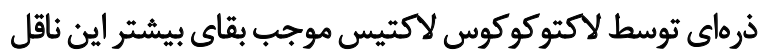
در معله و روده مي تُودي. زين و همكاران نشان دادند كه ايمنسازى ناشى از مصرف

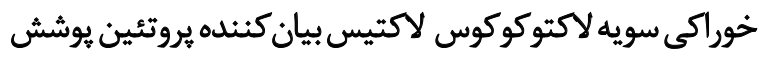

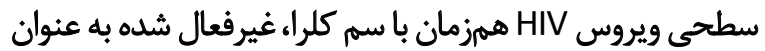

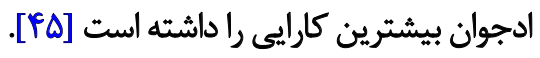

ارتقاى سطح ياسخ ايمنى با استفاده همزمان لاكتوكوكوس

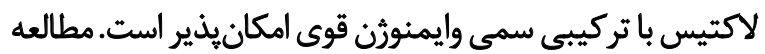

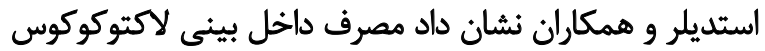

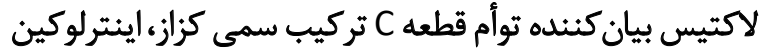

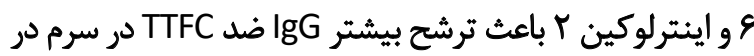

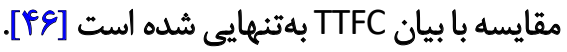
مصرف توأم لاكتوكوكوس لاكتيس بيانكننده اينترلوكين

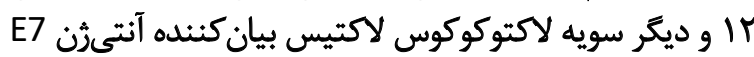

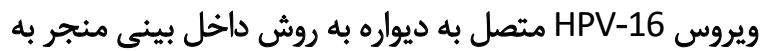

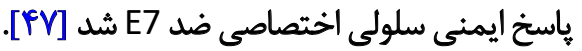

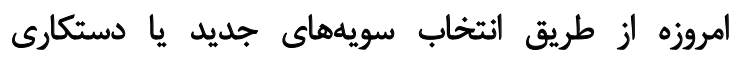

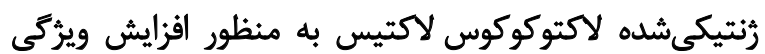

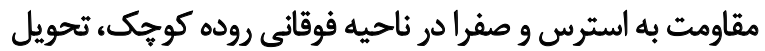

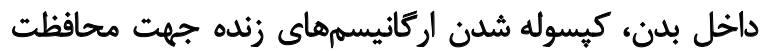

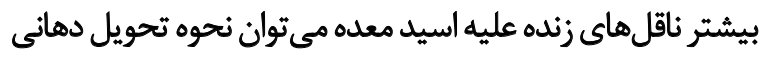
واكسنهاى لاكتوكوكوس لاكتيس را ارتقا داد.

استيدلر و همكارانش، ناقل لاكتوكوكوس لاكتيس كيسوله

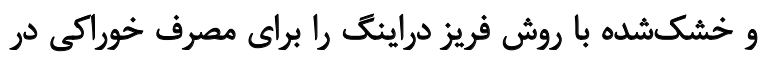

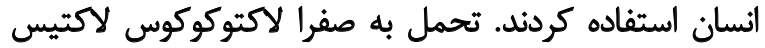

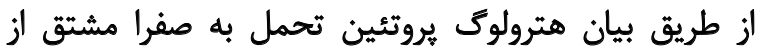


است [1].

لاكتوكوى نوتركيب به عنوان ميزبانى ايمن از نوع درجيه

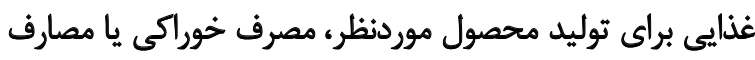

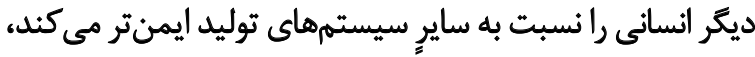

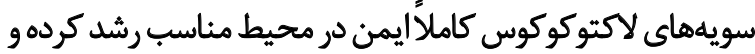

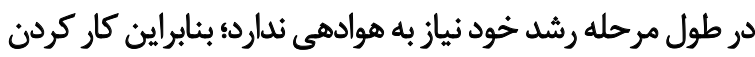

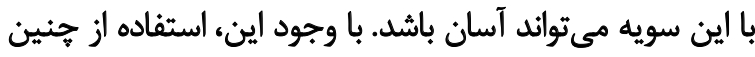

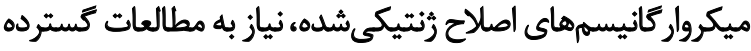

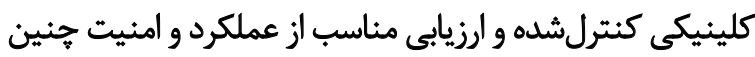
داروهايى؛ بهويثه براى انسان دارد.

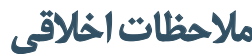

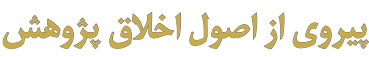

اين مقاله توسط كميته تحقيقات اخلاقى دانشعاه علومبزشكى اراك با شماره و9/99 1 إن تأييد شده است.

$$
\text { إماه }
$$

اين تحقيق هيج كَونه كمك مالى از سازمان هاى ثأمين مالى در

بخش هاى عمومى ، تجارى يا غير انتثفاعى دريافت نكرد.

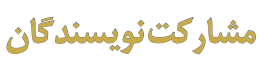

تمامى نويسندكان معيارهاى استاندارد نويسندكى بر اساس

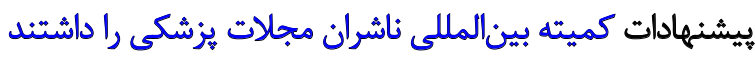
و همغى به يك اندازه در نتارش مقاله سهيم بودند.

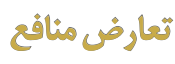

بنابر اظهار نويسندكان اين مقاله تعارض منافع ندارد. 


\section{References}

[1] Pontes DS, de Azevedo MS, Chatel JM, Langella P, Azevedo V, Miyosh A. Lactococcus lactis as a live vector: Heterologous protein production and DNA delivery systems. Protein Expr Purif. 2011; 79(2):165-75. [DOI:10.1016/j.pep.2011.06.005] [PMID]

[2] Chen S, Zhang R, Duan G, Shi J. Food-grade expression of Helicobacter pylori ureB subunit in Lactococcus lactis and its immunoreactivity. Curr Microbiol. 2011; 62(6):1726-31. [DOI:10.1007/s00284-0119920-6] [PMID]

[3] Izadjoo MJ, Bhattacharjee AK, Paranavitana CM, Hadfield TL, Hoover DL. Oral vaccination with Brucella melitensis WR201 protects mice against intranasal challenge with virulent Brucella melitensis $16 \mathrm{M}$. Infect Immun. 2004; 72(7):4031-9. [DOI:10.1128/IAI.72.7.40314039.2004] [PMID] [PMCID]

[4] Alton GG. Control of Brucella melitensis infection in sheep and goatsa review. Trop Anim Health Prod. 1987; 19(2):65-74. [DOI:10.1007/ BF02297320] [PMID]

[5] Minas A, Minas M, Stournara A, Tselepidis S. The "effects" of Rev-1 vaccination of sheep and goats on human brucellosis in Greece. Prev Vet Med. 2004; 64(1):41-7. [DOI:10.1016/j.prevetmed.2004.03.007] [PMID]

[6] Wallach J, Ferrero M, Victoria Delpino M, Fossati C, Baldi P. Occupational infection due to Brucella abortus S19 among workers involved in vaccine production in Argentina. Clin Microbiol Infect. 2008; 14(8):805-7. [DOI:10.1111/j.1469-0691.2008.02029.x] [PMID]

[7] Miyoshi A, Bermúdez-Humarán LG, Ribeiro LA, Le Loir Y, Oliveira SC, Langella $\mathrm{P}$, et al. Heterologous expression of Brucella abortus GroEL heat-shock protein in Lactococcus lactis. Microb Cell Fact. 2006; 5(1):14. [DOI:10.1186/1475-2859-5-14] [PMID] [PMCID]

[8] Song AA, In LLA, Lim SHE, Rahim RA. A review on Lactococcus lactis: From food to factory. Microb Cell Fact. 2017; 16(1):55. [DOI:10.1186/ s12934-017-0669-x] [PMID] [PMCID]

[9] Khorasgani MR, Shafiei R. Traditional Yogurt as a Source of Lactobacilli and Other Lactic Acid Bacteria in Iran. In: Nagendra PS, editoe. Yogurt in health and disease prevention. Cambridge, Ma: Academic Press; 2017. pp. 285-94. [DOI:10.1016/B978-0-12-805134-4.00016-X]

[10] D'Silva I. Recombinant technology and probiotics. Int J Eng Technol. 2011; 3(4):288-93. http://citeseerx.ist.psu.edu/viewdoc/download? doi=10.1.1.411.7661\&rep=rep1\&type=pdf

[11] Margolles A, Moreno JA, Ruiz L, Marelli B, Magni C, de Los ReyesGavilán CG, et al. Production of human growth hormone by Lactococcus lactis. J Biosci Bioeng. 2010; 109(4):322-4. [DOI:10.1016/j. jbiosc.2009.10.006] [PMID]

[12] Zhang XJ, Duan G, Zhang R, Fan Q. Optimized expression of Helicobacter pylori ureB gene in the Lactococcus lactis Nisin-Controlled Gene Expression (NICE) system and experimental study of its immunoreactivity. Curr Microbiol. 2009; 58(4):308-14. [DOI:10.1007/ s00284-008-9349-8] [PMID]

[13] Langella P, Le Loir Y. Heterologous protein secretion in Lactococcus lactis: A novel antigen delivery system. Braz J Med Biol Res. 1999; 32(2). 191-8. [DOI:10.1590/S0100-879X1999000200007] [PMID]

[14] Papagianni M. Recent advances in engineering the central carbon metabolism of industrially important bacteria. Microb Cell Fact. 2012; 11(1):50. [DOI:10.1186/1475-2859-11-50] [PMID] [PMCID]
[15] Nouaille S, Ribeiro LA, Miyoshi A, Pontes D, Le Loir Y, Oliveira SC, et al. Heterologous protein production and delivery systems for Lactococcus lactis. Genet Mol Res. 2003; 2(1):102-11. https://www. researchgate.net/profile/Yves-Le-Loir-2/publication/224901319 Heterologous_protein_production_and_delivery_systems_for_Lactococcus lactis/links/Ofcfd509905bc589f5000000/Heterologousprotein-production-and-delivery-systems-for-Lactococcus-lactis.pdf

[16] Mozzi F, Raya R, Vignolo GM, Love JC. Biotechnology of lactic acid bacteria: Novel Applications. New Jersey: Wiley Online Library; 2015 [DOI:10.1002/9781118868386]

[17] Hu CX, Xu ZR, Li WF, Dong N, Lu P, Fu LL. Secretory expression of K88 (F4) fimbrial adhesin FaeG by recombinant Lactococcus lactis for oral vaccination and its protective immune response in mice. Biotechno Lett. 2009; 31(7):991-7. [DOI:10.1007/s10529-009-9966-8] [PMID]

[18] Desmond C, Fitzgerald GF, Stanton C, Ross RP. Improved stress tolerance of GroESL-overproducing Lactococcus lactis and probiotic Lactobacillus paracasei NFBC 338. Appl Environ Microbiol. 2004 70(10):5929-36. [DOI:10.1128/AEM.70.10.5929-5936.2004] [PMID] [PMCID]

[19] Sasan H. Cloning of EprA1 gene from Aeromonas hydrophila in Lactococcus lactis. Iran J Biotechnol. 2010; 8(3):192-7. http://www.ijbiotech.com/article_7120_464477b340289dbffcc78f80c3a5c492.pdf

[20] Komijani M, Bouzari M, Rahimi F. Detection of TEM, SHV and CTX$M$ antibiotic resistance genes in escherichia coli isolates from infected wounds. Med Lab J. 2017; 11(2):30-5. http://mlj.goums.ac.ir/ article-1-972-en.htm

[21] Komijani M, Shahin K, Barazandeh M, Sajadi M. Prevalence of extended-spectrum $\beta$-lactamases genes in clinical isolates of Pseudomonas aeruginosa. Med Lab J. 2018; 12(5):34-41. [DOI:10.29252/ mlj.12.5.34]

[22] Shahin K, Bouzari M, Komijani M, Wang R. A new phage cocktail against multidrug, ESBL-Producer isolates of Shigella sonnei and Shigella flexneri with highly efficient bacteriolytic activity. Microb Drug Resist. 2020; 26 (7):831-41. [DOI:10.1089/mdr.2019.0235] [PMID]

[23] Heyman M, Ménard S. Probiotic microorganisms: How they affect intestinal pathophysiology. Cell Mol Life Sci. 2002; 59(7):1151-65. [DOI:10.1007/s00018-002-8494-7] [PMID]

[24] Reese KA, Lupfer C, Johnson RC, Mitev GM, Mullen VM, Geller BL, et al. A novel lactococcal vaccine expressing a peptide from the $M 2$ antigen of $\mathrm{H} 5 \mathrm{~N} 2$ highly pathogenic avian influenza $A$ virus prolongs survival of vaccinated chickens. Vet Med Int. 2013; 2013:316926. [DOI:10.1155/2013/316926] [PMID] [PMCID]

[25] Bermúdez-Humarán LG, Cortes-Perez NG, Lefèvre F, Guimarães $\mathrm{V}$, Rabot S, Alcocer-Gonzalez JM, et al. A novel mucosal vaccine based on live Lactococci expressing E7 antigen and IL-12 induces systemic and mucosal immune responses and protects mice against human papillomavirus type 16-induced tumors. J Immunol. 2005; 175(11):7297-302. [DOI:10.4049/jimmunol.175.11.7297] [PMID]

[26] Pei H, Liu J, Cheng Y, Sun C, Wang C, Lu Y, et al. Expression of SARS-coronavirus nucleocapsid protein in Escherichia coli and Lactococcus lactis for serodiagnosis and mucosal vaccination. Appl Microbiol Biotechnol. 2005; 68(2):220-7. [DOI:10.1007/ s00253-004-1869-y] [PMID] [PMCID]

[27] Bahey-El-Din M, Gahan CG, Griffin BT. Lactococcus lactis as a cell factory for delivery of therapeutic proteins. Curr Gene Ther. 2010 10(1):34-45. [DOI:10.2174/156652310790945557] [PMID] 
[28] de Azevedo MS, Innocentin S, Dorella FA, Rocha CS, Mariat D, Pontes DS, et al. Immunotherapy of allergic diseases using probiotics or recombinant probiotics. J Appl Microbiol. 2013; 115(2):319-33. [DOI:10.1111/jam.12174] [PMID]

[29] Zuercher AW, Weiss M, Holvoet S, Moser M, Moussu H, van Overtvelt L, et al. Lactococcus lactis NCC 2287 alleviates food allergic manifestations in sensitized mice by reducing IL-13 expression specifically in the ileum. Clin Dev Immunol. 2012; 2012:485750. [DOI:10.1155/2012/485750] [PMID] [PMCID]

[30] Steidler L, Rottiers P, Coulie B. Actobiotics ${ }^{\mathrm{TM}}$ as a novel method for cytokine delivery. Ann N Y Acad Sci. 2009; 1182(1):135-45. [DOI:10.1111/ j.1749-6632.2009.05067.x] [PMID]

[31] Luerce TD, Gomes-Santos AC, Rocha CS, Moreira TG, Cruz DN, Lemos $L$, et al. Anti-inflammatory effects of Lactococcus lactis NCDO 2118 during the remission period of chemically induced colitis. Gut Pathog. 2014; 6:33. [DOI:10.1186/1757-4749-6-33] [PMID] [PMCID]

[32] Liong MT. Probiotics: A critical review of their potential role as antihypertensives, immune modulators, hypocholesterolemics, and perimenopausal treatments. Nutr Rev. 2007; 65(7):316-28. [DOI:10.1111/j.1753-4887.2007.tb00309.x] [PMID]

[33] Bahey-El-Din M, Gahan CG. Lactococcus lactis -based vaccines: Current status and future perspectives. Hum Vaccin. 2011; 7(1):106-9. [DOI:10.4161/hv.7.1.13631] [PMID]

[34] D'Souza R, Pandeya DR, Hong S-T. Review: Lactococcus lactis: An efficient Gram positive cell factory for the production and secretion of recombinant protein. Biomed Res. 2012; 23(1):1-7. https://www. biomedres.info/biomedical-research/review-lactococcus-lactis-anefficient-gram-positive-cell-factory-for-the-production-and-secretion-of-recombinant-protein.html

[35] JJørgensen CM, Vrang A, Madsen SM. Recombinant protein expression in Lactococcus lactis using the P170 expression system. FEMS Microbiol Lett. 2014; 351(2):170-8. [DOI:10.1111/1574-6968.12351] [PMID]

[36] Mohseni AH, Razavilar V, Keyvani H, Razavi MR, Khavari-Nejad RA. Oral immunization with recombinant Lactococcus lactis NZ9000 expressing human papillomavirus type 16 E7 antigen and evaluation of its immune effects in female C57BL/6 mice. J Med Virol. 2019; 91(2):296-307. [DOI:10.1002/jmv.25303] [PMID]

[37] Aliramaei MR, Khorasgani MR, Rahmani MR, Zarkesh Esfahani SH, Emamzadeh R. Expression of Helicobacter pylori CagL gene in Lactococcus lactis MG1363 and evaluation of its immunogenicity as an oral vaccine in mice. Microb Pathog. 2019; 142:103926. [DOI:10.1016/j. micpath.2019.103926] [PMID]

[38] Rezaei M, Rabbani Khorasgani M, Zarkesh Esfahani SH, Emamzadeh R, Abtahi H. Production of Brucella melitensis Omp16 protein fused to the human interleukin 2 in Lactococcus lactis MG1363 toward developing a Lactococcus-based vaccine against brucellosis. Can J Microbiol. 2020; 66(1):39-45. [DOI:10.1139/cjm-2019-0261] [PMID]

[39] Shigemori S, Watanabe T, Kudoh K, Ihara M, Nigar S, Yamamoto Y, et al. Oral delivery of Lactococcus lactis that secretes bioactive heme oxygenase-1 alleviates development of acute colitis in mice. Microb Cell Fact. 2015; 14:189. [DOI:10.1186/s12934-015-0378-2] [PMID] [PMCID]

[40] Mantis NJ, Rol N, Corthésy B. Secretory IgA's complex roles in immunity and mucosal homeostasis in the gut. Mucosal Immunol. 2011; 4(6):603-11. [DOI:10.1038/mi.2011.41] [PMID] [PMCID]

[41] Bermúdez-Humarán LG. Lactococcus lactis as a live vector for mucosal delivery of therapeutic proteins. Hum Vaccin. 2009; 5(4):264-7. [DOI:10.4161/hv.5.4.7553] [PMID]
[42] Robert S, Steidler L. Recombinant Lactococcus lactis can make the difference in antigen-specific immune tolerance induction, the type 1 Diabetes case. Microb Cell Fact. 2014; 13 Suppl 1(Suppl 1):S11. [DOI:10.1186/1475-2859-13-S1-S11] [PMID] [PMCID]

[43] Steidler L, Neirynck S, Huyghebaert N, Snoeck V, Vermeire A, Goddeeris $B$, et al. Biological containment of genetically modified Lactococcus lactis for intestinal delivery of human interleukin 10. Nat Biotechnol. 2003; 21(7):785-9. [DOI:10.1038/nbt840] [PMID]

[44] Bahey-El-Din M, Casey PG, Griffin BT, Gahan CG. Efficacy of a Lactococcus lactis $\Delta$ pyrG vaccine delivery platform expressing chromosomally integrated hly from Listeria monocytogenes. Bioeng Bugs. 2010 1(1):66-74. [DOI:10.4161/bbug.1.1.10284] [PMID] [PMCID]

[45] Xin KQ, Hoshino Y, Toda Y, Igimi S, Kojima Y, Jounai N, et al. Immunogenicity and protective efficacy of orally administered recombinant Lactococcus lactis expressing surface-bound HIV Env. Blood. 2003; 102(1):223-8. [DOI:10.1182/blood-2003-01-0110] [PMID]

[46] Steidler L, Robinson K, Chamberlain L, Schofield KM, Remaut E, Le Page RW, et al. Mucosal delivery of murine Interleukin-2 (IL-2) and IL- 6 by recombinant strains of Lactococcus lactis coexpressing antigen and cytokine. Infect Immun. 1998; 66(7):3183-9. [DOI:10.1128/ IAI.66.7.3183-3189.1998] [PMID] [PMCID]

[47] Adachi K, Kawana K, Yokoyama T, Fuji T, Tomio A, Miura S, et al. Oral immunization with a Lactobacillus casei vaccine expressing human papillomavirus (HPV) type 16 E7 is an effective strategy to induce mucosa cytotoxic lymphocytes against HPV16 E7. Vaccine. 2010; 28(16):2810-7. [DOI:10.1016/j.vaccine.2010.02.005] [PMID]

[48] Villatoro-Hernandez J, Montes-de-Oca-Luna R, Kuipers OP. Targeting diseases with genetically engineered Lactococcus lactis and its course towards medical translation. Expert Opin Biol Ther. 2011; 11(3):261-7. [DOI:10.1517/14712598.2011.542138] [PMID]

[49] Taghinezhad-S S, Razavilar V, Keyvani H, Razavi MR, Nejadsattari T. Extracellular overproduction of recombinant Iranian HPV-16 E6 oncoprotein in Lactococcus lactis using the NICE system. Future Virol. 2018; 13(10):697-710. [DOI:10.2217/fvl-2018-0026]

[50] Rezaei M, Rabbani-Khorasgani M, Zarkesh-Esfahani SH, Emamzadeh $\mathrm{R}$, Abtahi $\mathrm{H}$. Prediction of the Omp16 Epitopes for the development of an Epitope-based vaccine against Brucellosis. Infect Disord Drug Targets. 2019; 19(1):36-45. [DOI:10.2174/1871526518666180709121653] [PMID]

[51] Mohseni AH, Taghinezhad-S S, Keyvani H, Razavilar V. Extracellular overproduction of E7 oncoprotein of Iranian human papillomavirus type 16 by genetically engineered Lactococcus lactis. BMC Biotechnology. 2019; 19(1):1-3. https://link.springer.com/article/10.1186/s12896019-0499-5

[52] Rahimi Y, Rabbani-Khorasgani M, Zarkesh-Esfahani SH, Emamzadeh $\mathrm{R}$, Keyvani Amineh $\mathrm{H}$, Rezaei $\mathrm{M}$. [Cloning of immunogenic domain of clostridium difficile toxin B in Lactococcus lactis to develop an oral vaccine based on Lactococcus against Clostridium difficile associated Colitis (Persian)]. J Ilam Univ Med Sci. 2019; 27(4):25-34. [DOI:10.29252/ sjimu.27.4.25]

[53] Gu Q, Song D, Zhu M. Oral vaccination of mice against helicobacter pylori with recombinant Lactococcus lactis expressing urease subunit B. FEMS Immunol Med Microbiol. 2009; 56(3):197-203. [DOI:10.1111/ j.1574-695X.2009.00566.x] [PMID] [PMCID]

[54] Bahey-El-Din M, Casey PG, Griffin BT, Gahan CG. Lactococcus lactisexpressing listeriolysin $\mathrm{O}$ (LLO) provides protection and specific CD8(+) $T$ cells against Listeria monocytogenes in the murine infection model. Vaccine. 2008; 26(41):5304-14. [DOI:10.1016/j.vaccine.2008.07.047] [PMID] [PMCID] 
[55] Daniel C, Sebbane F, Poiret S, Goudercourt D, Dewulf J, Mullet C, et al. Protection against Yersinia pseudotuberculosis infection conferred by a Lactococcus lactis mucosal delivery vector secreting LcrV. Vaccine. 2009; 27(8):1141-4. [DOI:10.1016/j.vaccine.2008.12.022] [PMID]

[56] Cheun HI, Kawamoto K, Hiramatsu M, Tamaoki H, Shirahata T, Igimi S, et al. Protective immunity of SpaA-antigen producing Lactococcus lactis against Erysipelothrix rhusiopathiae infection. J Appl Microbiol. 2004; 96(6):1347-53. [DOI:10.1111/j.1365-2672.2004.02283.x] [PMID]

[57] Sim AC, Lin W, Tan GK, Sim MS, Chow VT, Alonso S. Induction of neutralizing antibodies against dengue virus type 2 upon mucosal administration of a recombinant Lactococcus lactis strain expressing envelope domain III antigen. Vaccine. 2008; 26(9):1145-54. [DOI:10.1016/j.vaccine.2007.12.047] [PMID]

[58] Perez CA, Eichwald C, Burrone O, Mendoza D. Rotavirus vp7 antigen produced by Lactococcus lactis induces neutralizing antibodies in mice. J Appl Microbiol. 2005; 99(5):1158-64. [DOI:10.1111/j.13652672.2005.02709.x] [PMID]

[59] Li YJ, Ma GP, Li GW, Qiao XY, Ge JW, Tang L, et al. Oral vaccination with the porcine rotavirus VP4 outer capsid protein expressed by Lactococcus lactis induces specific antibody production. J Biomed Biotechnol. 2010; 2010:708460. [DOI:10.1155/2010/708460] [PMID] [PMCID]

[60] Tang L, Li Y. Oral immunization of mice with recombinant Lactococcus lactis expressing porcine transmissible gastroenteritis virus spike glycoprotein. Virus Genes. 2009; 39(2):238-45. [DOI:10.1007/s11262-0090390-x] [PMID] [PMCID]

[61] Zhang ZH, Jiang PH, Li NJ, Shi M, Huang W. Oral vaccination of mice against rodent malaria with recombinant Lactococcus lactis expressing MSP-119. World J Gastroenterol. 2005; 11(44):6975-80. [DOI:10.3748/ wjg.v11.i44.6975] [PMID] [PMCID]

[62] Lee P, Faubert GM. Expression of the Giardia lamblia cyst wall protein 2 in Lactococcus lactis. Microbiology (Reading). 2006; 152(Pt 7):1981-1990. [DOI:10.1099/mic.0.28877-0] [PMID] 